\title{
Recovery of Fertility in Azoospermia Rats after Injection of Adipose-Tissue-Derived Mesenchymal Stem Cells: The Sperm Generation
}

\author{
Cihangir Cakici, ${ }^{1}$ Bugra Buyrukcu, ${ }^{1}$ Gokhan Duruksu, ${ }^{2}$ Ahmet Hakan Haliloglu, ${ }^{3}$ \\ Ayca Aksoy, ${ }^{2}$ Ayca Isık, ${ }^{1}$ Orhan Uludag, ${ }^{4}$ Huseyin Ustun, ${ }^{5}$ Cansu Subası, ${ }^{2}$ and Erdal Karaoz ${ }^{2}$ \\ ${ }^{1}$ Ankalife IVF and Women Health Centre, Ankara, Turkey \\ ${ }^{2}$ Stem Cell Department, Institute of Health Sciences, Kocaeli University Center for Stem Cell and Gene Therapies Research and Practice, \\ Izmit, 41380 Kocaeli, Turkey \\ ${ }^{3}$ Urology Department, Faculty of Medicine, Ufuk University, Ankara, Turkey \\ ${ }^{4}$ Department of Pharmacology, Faculty of Pharmacy, Gazi University, Ankara, Turkey \\ ${ }^{5}$ Pathology Department, Ankara Hospital, Ankara, Turkey
}

Correspondence should be addressed to Erdal Karaoz; ekaraoz@hotmail.com

Received 10 October 2012; Revised 6 December 2012; Accepted 9 December 2012

Academic Editor: Thomas Skutella

Copyright (C) 2013 Cihangir Cakici et al. This is an open access article distributed under the Creative Commons Attribution License, which permits unrestricted use, distribution, and reproduction in any medium, provided the original work is properly cited.

The recent reports on the treatment of azoospermia patients, in which spermatozoa could not be traced in their testes, are focused more on the potential use of adult stem cells, like mesenchymal stem cells (MSCs). The aim of this study was to demonstrate the potential use of MSCs derived from adipose tissue in the treatment of azoospermia using rat disease models. After busulfan application, the rats $(n=20)$ were injected with the $\mathrm{GFP}^{+}$MSCs into left rete testes. After 12 weeks, the testes with cell injection (right testes) were compared to control (left testes) after dimensional and immunohistochemical analyses. Testes treated with MSCs appeared morphologically normal, but they were atrophic in rats without stem cell treatment, in which the seminiferous tubules were empty. Spermatogenesis was detected, not in every but in some tubules of cell-treated testes. $\mathrm{GFP}^{+} / \mathrm{VASA}^{+}$and $\mathrm{GFP}^{+} / \mathrm{SCP1}^{+}$ cells in testes indicated the transdifferentiation of MSCs into spermatogenetic cells in the appropriate microenvironment. Rats with cell treatment were mated to show the full recovery of spermatogenesis, and continuous generations were obtained. The expression of GFP was detected in the mesenchymal stem cells derived from adipose tissue and bone marrow and also in the sperms of offspring. In conclusion, MSCs might be studied for the same purpose in humans in future.

\section{Introduction}

The self-renewal and the multilineage differentiation capacities of adult stem cells (ASCs) show great promises for regenerative medicine. Despite of the greater differentiation potential of embryonic stem cells (ESCs) compared to ASCs, ethical concerns and governmental restrictions are the main obstacles of the ESCs standing in the way of their clinical applications [1]. On the other hand, bone-marrowderived MSCs (BM-MSCs) are among the mostly studied ASCs, and their potential to treat a wide variety of diseases, including erectile dysfunction and male infertility, was demonstrated. Alternatively, adipose-tissue-derived MSCs (AT-MSCs) could be used in future clinical applications instead of bone marrow stem cells due to their comparable differentiation and therapeutic potential, but AT-MSCs are easier and safer to obtain [1-18].

The stem cells were relatively lately adapted in andrology researches on erectile dysfunction and infertility as potential therapeutic agents. The studies related in this area showed that ESC could participate in spermatogenesis by forming functional male germ cells in vitro or by supporting the maturation of primordial germ cells into haploid male gametes [19-21]. Nayernia et al. reported germ cell line formation 
from pluripotent teratocarcinoma cells in 2004, and after two years, the generation of offspring mice from ESC-derived germ cells was succeeded for the first time [22, 23]. The milestone in adult stem cell research to treat the infertility was the murine BM-MSC differentiation into male germ cells that was succeeded by the same group in 2006 [24]. The differentiation of BM-MSCs into germ cells, Sertoli cells, and Leydig cells was demonstrated in busulfan-treated infertile mice $[25,26]$. MSCs derived from human fetal lung and umbilical cord were also shown to differentiate into sperm like cells $[27,28]$. Due to their germ cell formation capacity in vitro, they suggested that those cells could be the base for a treatment of male infertility. These recent studies reveal that the treatment of diseases, like male infertility and testosterone deficiency, was possible by ASCs.

In this study, the mesenchymal-stem-cell-based therapy for azoospermia was aimed. For this purpose, allogenic ATMSCs were injected into testicles of azoospermia rat models to recover the infertility. A strategy was herewith proposed for the treatment of azoospermia by intratesticular transfer of adult stem cells.

\section{Materials and Methods}

2.1. Animals. Animals were housed in the Laboratory Animal Care Center (Kobay A.S., Ankara, Turkey). All animal procedures were approved by the local ethical animal research committee. Male Wistar rats $(n=32)$ aged $8-12$ weeks were housed in temperature-controlled rooms $\left(20-22^{\circ} \mathrm{C}\right)$ under $12 \mathrm{~h}$ light/dark cycle. Later, female Wistar rats $(n=24)$ aged 8-16 weeks were housed for mating. The rats were fed with standard commercial chow diet ad libitum.

2.2. Experimental Design. MSCs were isolated from rat $(n=$ 8 ) adipose tissue and labeled with GFP. The rest of male rats $(n=24)$ were sterilized with busulfan. After assessing the infertile status by analyzing the testes of rats $(n=4)$, the right testis of each rat $(n=20)$ was injected with MSCs. The other testis was left as control. After twelve weeks, testes of four animals were removed for dimension analysis. For immunohistochemical analyses, four additional rats were excised. The remaining male rats $(n=12)$ were mated with female rats $(n=24)$. Cells from offspring were analyzed for GFP expression.

\subsection{Isolation and Culture of Rat Adipose-Tissue-Derived} Mesenchymal Stem Cells (rAT-MSCs). Rats $(n=8)$ were anesthetized by injection of $10 \mathrm{mg} / \mathrm{kg}$ Xylazine and $75 \mathrm{mg} / \mathrm{kg}$ Ketamine. $1-2 \mathrm{~cm}^{3}$ of preperitoneal adipose tissue was removed. Tissue samples were washed several times with Hanks' balanced salt solution supplemented with 5\% antibiotic-antimycotic solution (Gibco Life Technologies, Paisley, UK), and vascular structures were removed. The yellowish white tissue was minced and enzymatically digested in MEM medium (Gibco Life Technologies) containing $0.075 \%$ collagenase 2 (Sigma, St. Louis, MO) at $37^{\circ} \mathrm{C}$ for $60 \mathrm{~min}$. The cell suspension was filtered with $70 \mu \mathrm{m}$ sieve (Becton Dickinson Labware, Franklin Lakes, NJ). The cells were resuspended in MEM medium supplemented with 1\% penicillin/streptomycin and 15\% FBS (standard culture medium). After the centrifugation at $1200 \mathrm{rpm}$ for $10 \mathrm{~min}$, the cells were cultured in standard culture medium in $25 \mathrm{~cm}^{2}$ culture flasks. After 7 days, the medium was replaced with fresh medium and subsequently replaced twice a week. Erythrocytes and other non adhesive cells were removed from the culture. After reaching 70-80\% confluence, the cells were harvested with $0.025 \%$ trypsin-EDTA for $3 \mathrm{~min}$, collected by centrifugation, and subcultured at 1:3-1:4 ratio. The cells were counted by Trypan blue (Biological Industries, Kibbutz Beit Haemek, Israel). The blue staining of cells after mixing (1:1) was used as indicator of cell death.

2.4. Flow Cytometry. Undifferentiated rAT-MSCs were subjected to flow cytometry analysis. After passage 3 (P3), stem cells were harvested. Flow cytometry was performed using a FACS Calibur (BD Biosciences, San Jose, CA). Immunophenotyping analysis was performed against the following antigens: CD29, CD45, CD54, CD90, and CD106 (BD Biosciences).

2.5. Immunostaining of $r A T-M S C s$. For immunofluorescence staining, samples were rinsed briefly in PBS and fixed in ice-cold methanol for $10 \mathrm{~min}$. After permeabilization with $0.025 \%$ Triton X-100 (Merck, Darmstadt, Germany), the cells were incubated with $1.5 \%$ blocking serum (Santa Cruz Biotechnology, Heidelberg, Germany) in PBS for $30 \mathrm{~min}$ at $37^{\circ} \mathrm{C}$ followed by incubation overnight at $4^{\circ} \mathrm{C}$ with the primary antibody. After three PBS washes, cells were incubated with secondary antibodies for $25 \mathrm{~min}$. The samples were mounted with mounting medium containing DAPI (Santa Cruz Biotechnology).

Immunohistochemical (IHC) analyses were performed using the streptavidin-peroxidase method (UltraVision Plus Detection System, Thermo Scientific, Chesire UK). Cultured cells were fixed in ice-cold methanol with $0.3 \%$ hydrogen peroxide (Carlo Erba) for $15 \mathrm{~min}$. Cells were incubated with Ultra $\mathrm{V}$ Block for $5 \mathrm{~min}$ and incubated overnight at $4^{\circ} \mathrm{C}$ with the primary antibodies and for $15 \mathrm{~min}$ with secondary antibody at room temperature. After treatment with streptavidin peroxidase for $15 \mathrm{~min}$ at room temperature, signals were detected by the AEC kit (Zymed Laboratories, Inc., San Francisco, CA). The cells were counter-stained with hematoxylin (Santa Cruz Biotechnology). The list of primary antibodies was given in Table 1 .

2.6. In Vitro Differentiation. To induce adipogenic differentiation, cells were seeded onto 6-well plates (P3; 3000 cells $/ \mathrm{cm}^{2}$ ) and cultured with Mesencult MSC Basal Medium supplemented with $10 \%$ adipogenic supplement (Stem Cell Technologies Inc., Vancouver, BC, Canada) and 1\% penicillin/streptomycin for 3 weeks. The medium was refreshed every 2-4 days. Intracellular lipid droplets indicate adipogenic differentiation confirmed by Oil Red $\mathrm{O}$ staining ( $0.5 \%$ in methanol; Sigma-Aldrich).

For osteogenic differentiation, cells (P3; 3000 cells $/ \mathrm{cm}^{2}$ ) were seeded onto collagen I precoated cover slips in 6-well 
TABLE 1: Immunocytochemical properties of rAT-MSCs.

\begin{tabular}{|c|c|c|c|}
\hline Antibody/marker & Dilution & Source & Detection \\
\hline CD 26 & $1: 50$ & Santa Cruz Bio. & + \\
\hline CD 34 (C-18) & $1: 150$ & Santa Cruz Bio. & $\emptyset$ \\
\hline CD $45(\mathrm{H}-230)$ & $1: 150$ & Santa Cruz Bio. & $\emptyset$ \\
\hline CD $71(K-20)$ & $1: 150$ & Santa Cruz Bio. & $\emptyset$ \\
\hline CD105/Endoglin (M-20) & $1: 100$ & Santa Cruz Bio. & + \\
\hline c-Fos (4) & $1: 50$ & Santa Cruz Bio. & + \\
\hline Collagen II (2B1.5) & Predilute & Thermo Scientific & + \\
\hline Collagen Ial (D-13) & $1: 50$ & Santa Cruz Bio. & + \\
\hline$\beta$-tubulin & $1: 50$ & Santa Cruz Bio. & + \\
\hline Nestin (Rat-401) & $1: 50$ & Santa Cruz Bio. & + \\
\hline Vimentin (C-20) & $1: 100$ & Santa Cruz Bio. & + \\
\hline Fibronectin (EP5) & $1: 100$ & Santa Cruz Bio. & + \\
\hline ASMA & $1: 800$ & Thermo Scientific & + \\
\hline Myogenin (F5D) & Predilute & Thermo Scientific & + \\
\hline MAP 2a, b (AP20) & Predilute & Thermo Scientific & + \\
\hline GFAP & Predilute & Thermo Scientific & + \\
\hline Osteocalcin (FL-100) & $1: 50$ & Santa Cruz Bio. & + \\
\hline Osteonectin (SPARC) & $1: 50$ & Millipore & + \\
\hline Osteopontin (AKm2A1) & $1: 50$ & Santa Cruz Bio. & + \\
\hline Ki67 & $1: 300$ & Thermo Scientific & + \\
\hline PCNA & $1: 200$ & Thermo Scientific & + \\
\hline Tenascin-C & $1: 50$ & Santa Cruz Bio. & + \\
\hline Cytokeratin 18 & $1: 50$ & Santa Cruz Bio. & $\emptyset$ \\
\hline
\end{tabular}

+: positive; Ø: lack of marker expression.

plates. The differentiation medium (MEM supplemented with $0.1 \mu \mathrm{M}$ dexamethasone (Sigma-Aldrich), $0.05 \mu \mathrm{M}$ ascorbate-2-phosphate (Wako Chemicals, Richmond, VA, USA), $10 \mathrm{mM} \beta$-glycerophosphate (Sigma-Aldrich), $1 \%$ antibiotic/antimycotic, and 10\% FBS) was replaced twice a week. After four weeks, osteogenic differentiation was assessed by Alizarin red staining. For Alizarin red staining, cells were fixed for $5 \mathrm{~min}$ in ice-cold $70 \%$ ethanol. The cells were stained with Alizarin red solution (2\%, $\mathrm{pH} 4.2)$ for 30 s. Stained cells were dehydrated in pure acetone, fixed in acetone-xylene $(1: 1)$ solution, and cleared with xylene.

To induce neurogenic differentiation, cells (P3) seeded on collagen-I-coated cover slips were cultivated until 70\% confluency. Cells were cultured for 3-5 days in differentiation medium (MEM supplemented with $0.5 \mathrm{mM}$ isobutylmethylxanthine (IBMX), $10 \mathrm{ng} / \mathrm{mL}$ brain-derived neurotrophic factor (BDNF), $10 \mathrm{ng} / \mathrm{mL}$ epidermal growth factor (EGF), $10 \mathrm{ng} / \mathrm{mL}$ basic fibroblast growth factor (bFGF), 20\% neural stem cell proliferation supplements (Stem Cell Technologies Inc.) and $1 \%$ penicillin-streptomycin). Differentiation was assessed by immunofluorescence staining of GFAP (SC-71141), HNK (SC-49034), Neurofilament (SC-12980), beta-tubulin (SC9935), beta3-tubulin (SC-69965), c-Fos (SC-52), Nestin (SC23927), and Eno2 (SC-59538). All antibodies were obtained from Santa Cruz Biotechnology.

2.7. In Vitro Tube Formation Assay. To show the angiogenic potential of rAT-MSCs, tube formation was induced by culturing on Matrigel (Basement Membrane Matrix, LDEVFree, BD Biosciences, Cat. No. 354234). $100 \mu \mathrm{L}$ of Matrigel was spread on the prechilled surface of each 24 well of the plate and incubated in standard culture medium $(1: 1)$ at $37^{\circ} \mathrm{C}$ for at least $30 \mathrm{~min}$ for polymerization. Cells suspended in serum supplemented medium were seeded on Matrigelcoated wells to a final density of $2.5 \times 10^{4}$ cells $/ \mathrm{cm}^{2}$. The formation of tube-like structures was observed after $24 \mathrm{~h}$.

2.8. GFP Labeling of rAT-MSCs. The plasmid was supplied from Clontech (Palo Alto, CA), amplified in E. coli strain XL1, and purified by Endofree PlasmidMaxi kit (Qiagen, Hilden, Germany). GFP coding gene was located downstream of the CMV (murine leukemia virus) constitutive promoter on vector. The cells were transfected by Neon Transfection System (Invitrogen Life Technologies, Carlsbad, CA) with the following parameters: $990 \mathrm{~V}, 40 \mathrm{~ms}$, and 2 pulses. $2 \times 10^{5}$ cells were mixed with $1 \mu \mathrm{g}$ plasmid DNA in $10 \mu \mathrm{L}$ transfer buffer. The transformed cells were cultured in MEM-medium supplied with $15 \%$ FBS. After $48 \mathrm{~h}$, the cells were selected for antibiotic resistance toward G418 $(400 \mu \mathrm{g} / \mathrm{mL})$ for 6 weeks. Then, the GFP stability of cells was monitored by continuous culturing for 4 passages, and the number of $\mathrm{GFP}^{+}$cells was counted in flow cytometer. The integration of GFP gene into genome was checked by Real-Time PCR, and the copy number of integration in chromosome was determined. 
2.9. Busulfan Treatment of Rats and Cell Transplantation. For long-term infertility, rats $(n=24)$ were injected with alkylating agent, busulfan (15 mg/kg; Sigma-Aldrich), twice with 14 days of interval to disrupt spermatogenesis. Once every 4 weeks, gonadotropin-releasing hormone $(\mathrm{GnRH})$ agonist, leuprolide acetate (Lucrin, Abbott AS, Istanbul, Turkey), was administered subcutaneously ( $1.5 \mathrm{mg} / \mathrm{rat})$ for 12 weeks until the animal was analyzed, according to the previous reports [29]. The effectiveness of this process was determined first by measuring testis size and weight. To confirm the effect, testes of 4 rats were removed, fixed in Bouin's fluid (9\% formaldehyde, $5 \%$ acetic acid, $0.9 \%$ picric acid in water) and embedded in paraffin. To evaluate the spermatogenetic activity in tubules by histological analysis, the sections were stained with hematoxylin.

AT-MSCs' suspension was mixed with sterile toluidine blue $(1: 1, \mathrm{v} / \mathrm{v})$. Rete testis was identified by using stereomicroscope (Olympus, KL1500LCD), and these cells were injected into the lumen of the seminiferous tubules of recipient rat testis $(n=20)$, as described before [30]. $100 \mu \mathrm{L}$ of AT-MSCs' mixture $\left(10^{6}\right.$ cells) was injected into the rete testis of the left testicle (Figure 4) under stereomicroscope (Olympus, SZX7) using FemotoJet semiautomatic microinjector (Brinkmann Instruments Inc., Westbury, NY). The toluidine blue served as a marker to monitor the success of the injection. The untreated right testicle was served as control.

2.10. Analysis of Recipient Rats. Twelve weeks after cell transplantation, the testes of rats $(n=4)$ were analyzed dimensionally. The volume of testis was estimated by Cavalieri's principle. To localize the GFP-tagged rAT-MSCs in testes, rats $(n=4)$ were sacrificed for immune staining. Testis tissue samples were removed, fixed in formalin (10\%, $\mathrm{pH} 7.0-7.6)$ for $24 \mathrm{~h}$, and embedded in paraffin. Transversal serial sections ( $4 \mu \mathrm{m}$ thick) were taken. GFP labeled rAT-MSCs, used for cell tracking after injection, were double-stained on sections for GFP, and antigen of interest. Slides were deparaffinized with two changes of xylene for $5 \mathrm{~min}$ each and rehydrated in a series of graded alcohol solutions. Sections were antigen retrieved using a steamer-citrate buffer antigen retrieval method. Endogenous peroxidase was inhibited by incubation with fresh $3 \% \mathrm{H}_{2} \mathrm{O}_{2}$ in PBS buffer. Nonspecific staining was blocked with the mixture of two different serums (with respect to the type of the antibodies used for blotting) in 1.5\% $\mathrm{PBS}$ for $30 \mathrm{~min}$ at room temperature. Afterwards, the sections were incubated in the mixture of two primary antibodies in a pairwise fashion against GFP (SC-9996 or SC-5385) and vimentin (SC-7557), VASA (SC-67185), or SCP1 (SC-20837) for $1 \mathrm{~h}$ at RT. The sections were incubated in a mixture of two appropriate fluorescent-conjugated secondary antibodies and were mounted with mounting medium containing DAPI (Santa Cruz).

2.11. Mating the Rats. Female rats $(n=24)$ were mated during the proestrus phase with male rats $(n=12)$ with rAT-MSCs' transplantation. Every male rat was cohabitated with two female rats in polycarbonate cages until evidence of mating, vaginal plug, was observed.
2.12. Detection of GFP Gene in Rat Chromosomal DNA. To determine whether these injected cells contributed in spermatogenesis and support the formation of offspring, GFP gene was traced in the genome of rat offspring. For this purpose, chromosomal DNA was isolated by QIAamp DNA Blood Mini Kit (Qiagen) from the blood samples of rat offspring according to the kit procedures. The GFP gene was amplified first by conventional PCR using the following primer pairs: $5^{\prime}$-cttgttgaattagatggtgatg $/ 5^{\prime}$ ctgttacaaactcaagaaggacc. Template DNA-free PCR reaction was used as negative control. The gene copy number in DNA samples was estimated by real-time PCR using the same primer pairs and Power SYBR Green Master Mix (Applied Biosystems Life Technologies) in amplification reaction. Sox2 gene was amplified as reference for each DNA sample with the following primer pairs: $5^{\prime}$-atgtacaacatgatggagacg $/ 5^{\prime}$ tcacatgtgtgagaggggcagtg. The GFP gene in genome was further confirmed by Southern blot hybridization assay [31]. $5 \mu \mathrm{g}$ of rat chromosomal DNA was incubated with XbaI and XhoI restriction enzymes (10 U/each; Fermentas, Vilnius, Lithuania) for $16 \mathrm{~h}$ at $37^{\circ} \mathrm{C}$, blotted on positively charged nylon membrane (Roche) by capillary action, and detected by DIG (digoxigenin) Nucleic Acid Detection Kit (Roche) according to the protocol by manufacturer. Oligonucleotide probe for detection was synthesized by random labeling of GFP gene with DIG-labeled nucleotides. The detection of chemiluminescence was performed by DNR Bio-Imagining Systems (MF-ChemiBIS 3.2, Jerusalem, Israel).

\subsection{Detection of GFP Expression in Offspring's rBM-MSCs} and rAT-MSCs. To observe the GFP expression in MSCs of offspring, both adipose-tissue- and bone-marrow-derived MSCs were analyzed. rAT-MSCs were isolated and characterized by the methods described previously (Sections 2.32.6). rBM-MSCs were isolated with the following procedure. Under sterile conditions, both rat femur and tibiae were excised, and the bone marrow was extruded by flushing with standard culture medium using 21-gauge needle. Marrow plug suspension was dispersed by pipetting, successively filtered through $70 \mu \mathrm{m}$ mesh nylon filter (BD Biosciences, Bedford, MA), and centrifuged at $200 \mathrm{xg}$ for $10 \mathrm{~min}$. The bone marrow was diluted to $1: 3$ with PBS and layered over a Ficoll-histopaque gradient $(1.077 \mathrm{~g} / \mathrm{mL}$, Sigma). The low-density mononuclear cells were collected, washed twice with PBS, counted, and plated in tissue culture flasks at a density of $1.4 \times 10^{5}$ cells $/ \mathrm{cm}^{2}$ in standard culture medium. The MSCs were isolated based on their ability to adhere on plastic. By replacing the culture medium with fresh medium, the unattached cells were removed from the culture, and the culture was allowed to grow further. Cells at 70$80 \%$ confluency were harvested with $0.25 \%$ trypsin-EDTA solution after washing with $\mathrm{Ca}^{2+}-\mathrm{Mg}^{2+}$-free PBS. Both rBMMSCs and rAT-MSCs from offspring were cultured to passage 2 (P2), and immunofluorescence staining was performed as previously described in Section 2.5. To detect the GFP expression in stem cells, anti-GFP antibody was used.

Both rBM-MSCs and rAT-MSCs from offspring were cultured to passage 2 (P2), and immunofluorescence staining 


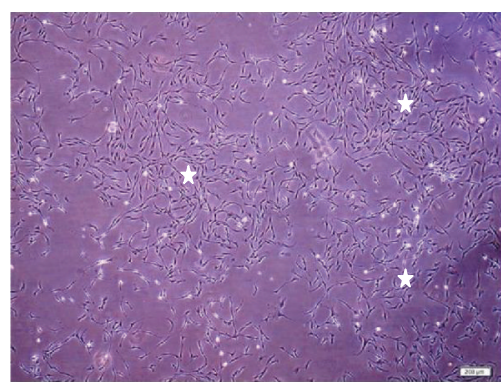

(a1)

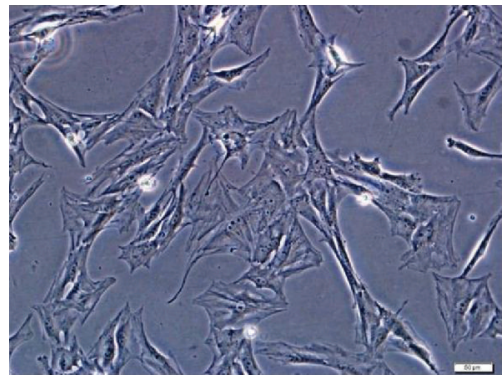

(a3)

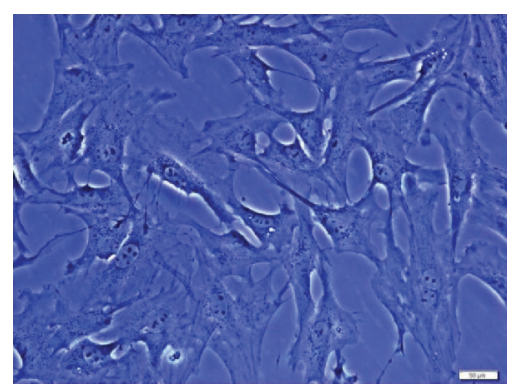

(a2)

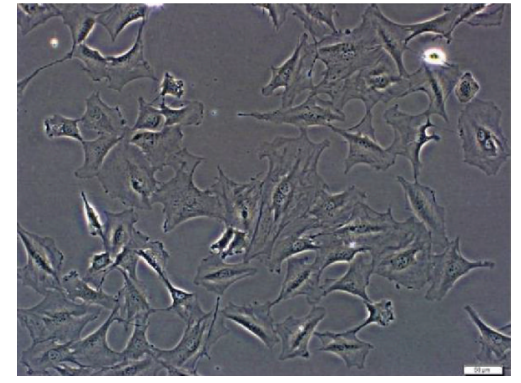

(a4)

(a)
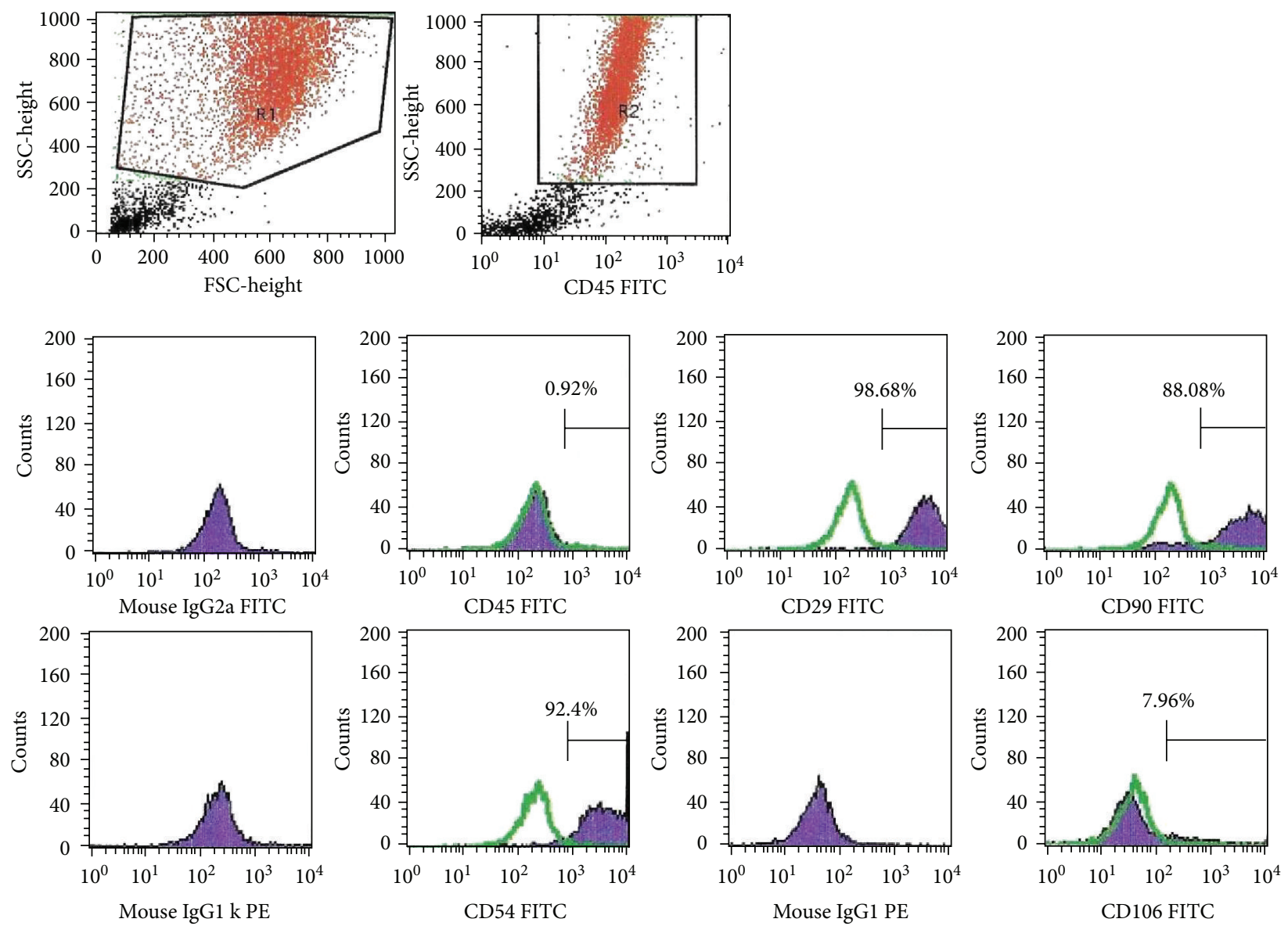

(b)

FIGURE 1: Morphological and phenotypic characteristics of rAT-MSCs. During the onset of culture (al: P0-5th day), the isolated cells from rat adipose tissue formed single-cell-derived colonies (arrows). After the next days and passages, most of these SCs exhibited large, flattened or fibroblast-like morphology (a2: P0-7th day, a3: P1-2th day, and a4: P3-1th day). (b) A representative flow cytometry analysis of cell-surface markers of rAT-MSCs at P3; cells were labeled with antibodies against hematopoietic (CD45) and MSC markers (CD29, CD54 and CD90) and with vascular cell adhesion protein 1 (CD106). (green line: histogram of isotype control immunoglobulin). 


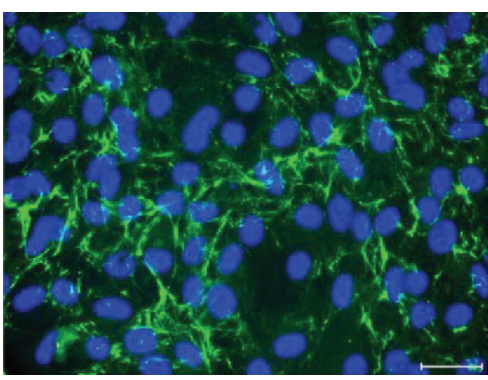

(a)

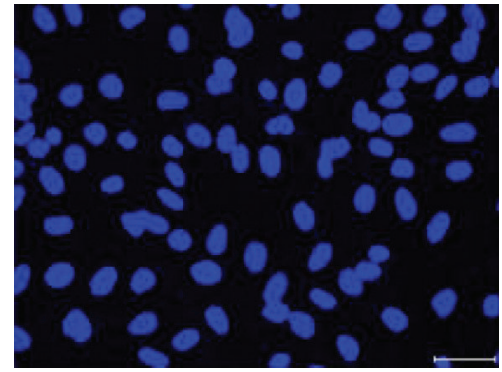

(d)

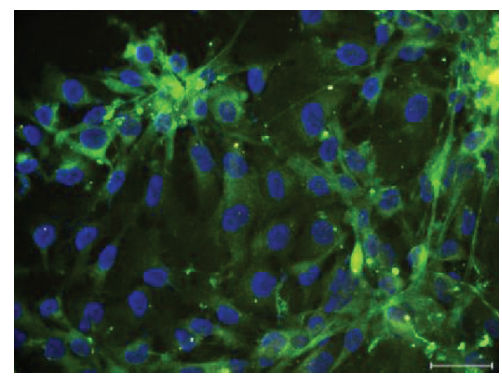

(g)

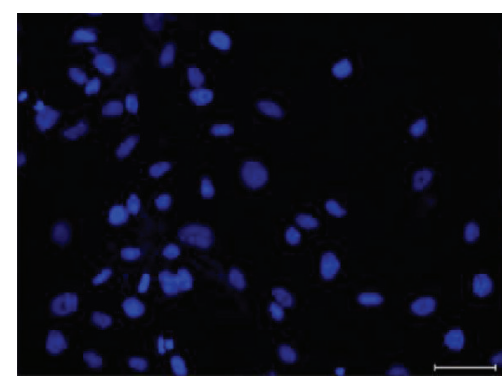

(b)

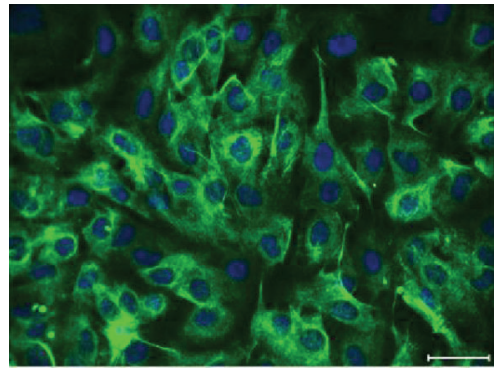

(e)

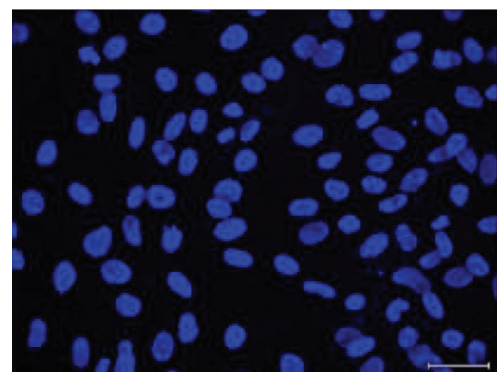

(h)

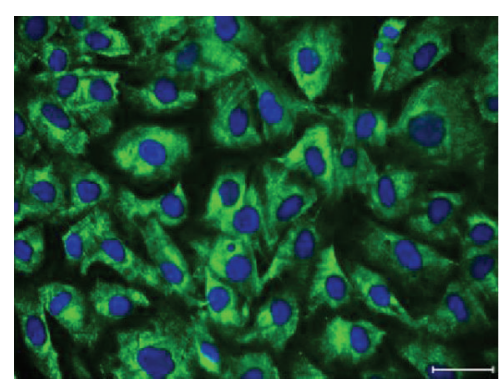

(c)

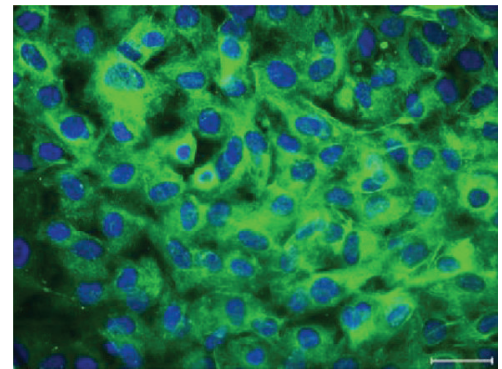

(f)

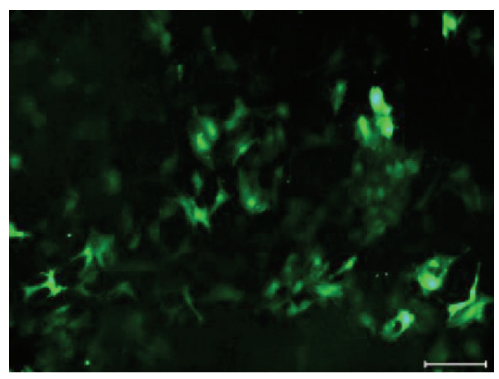

(i)

FIGURE 2: Immunofluorescence staining of rAT-MSCs for fibronectin (a), CD34 (b), GFAP (c), CD45 (d), Nestin (e), Vimentin (f), Map2a, b $(\mathrm{g})$, and Cytokeratin 18 (h). Staining pattern was cytoplasmic for fibronectin, GFAP, nestin, and vimentin; and both membranous and cytoplasmic for Map2a, b. After transfection, rAT-MSCs showed GFP ${ }^{+}$immunostaining (i). Nuclei were labeled with DAPI (blue). Scale bars: $50 \mu \mathrm{m}$.

was performed as previously described. To detect the GFP expression in stem cells, anti-GFP antibody was used.

To show the $\mathrm{GFP}^{+}$sperms, the testes of offspring (1st generation) were removed and cut in small sizes in $\mathrm{Ca}^{2+}$ $\mathrm{Mg}^{2+}$-free Hank's Balanced Salt Solution (HBSS with, Gibco Life Technologies) with $0.35 \mathrm{~g} / \mathrm{L}$ sodium bicarbonate and $1 \mathrm{~g} / \mathrm{L}$ D-glucose. Large tissue particles were removed, and sperm cells were collected on glass slides in the cytocentrifuge (1500 rpm, $10 \mathrm{~min})$. Slides were stained with antibody to GFP (Santa Cruz, sc-5385). The nuclei were labeled with DAPI.

2.14. Statistical Analysis. A computer program (SPSS 10.0) was used for statistical analysis. The results were expressed as means \pm standard deviation (SD). Two-tailed paired $t$ test was used for the comparison of the groups. Differences between the groups were considered as statistically significant when $P<0.05$ and highly significant when $P<0.01$.

\section{Results}

3.1. Culture of $r A T-M S C$. MSCs attached to the culture flasks sparsely and displayed a fibroblast-like, spindle-shaped morphology during the initial days of incubation. Following 3-4 days of incubation, proliferation started and the cells gradually grew into small colonies. During culture, adjacent colonies interconnected with each other, and a monolayer confluence was obtained after 12-15 days of incubation. In later passages, MSCs exhibited large, flattened fibroblastlike morphology (Figures 1(a1)-1(a4)) and did not change throughout 25 passages. Tests for bacterial and mycoplasma contamination were negative. The viability of cells was higher than $95 \%$, determined by Trypan blue staining of cells. rATMSCs expressed CD29, CD54, and CD90, but not CD45 and CD106 (Figure 1(b)) and maintained their phenotype in the following passages. 


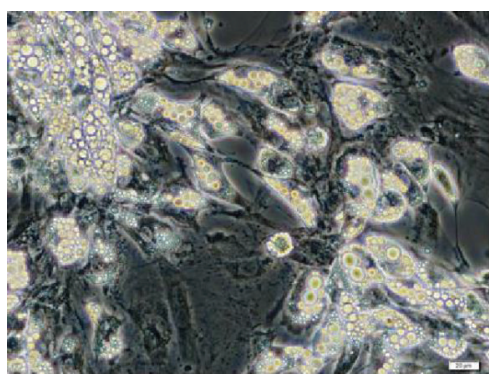

(a)

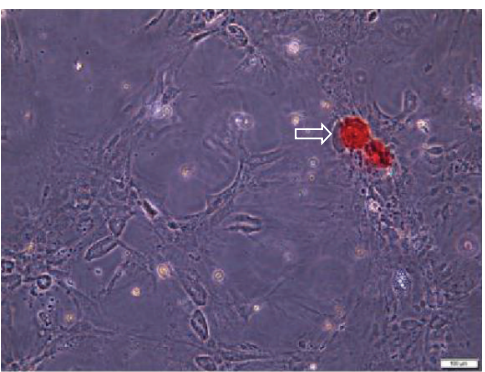

(d)

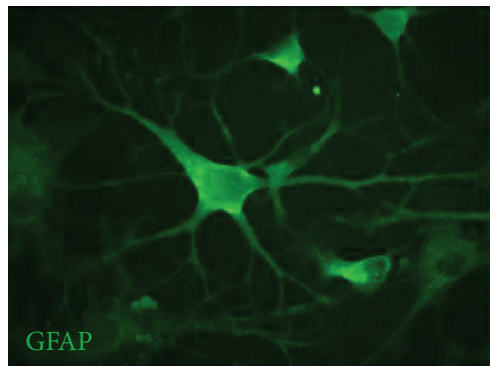

(g1)

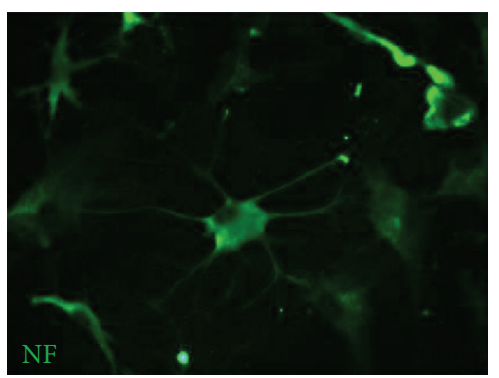

(h1)

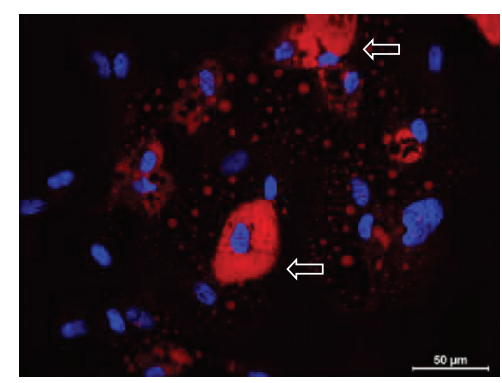

(b)

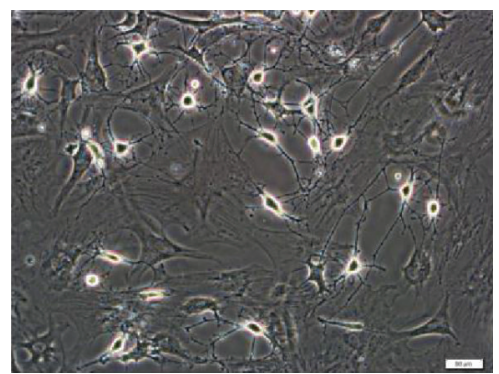

(e)

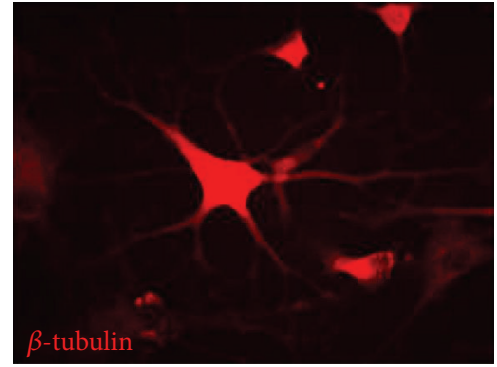

(g2)

(g)

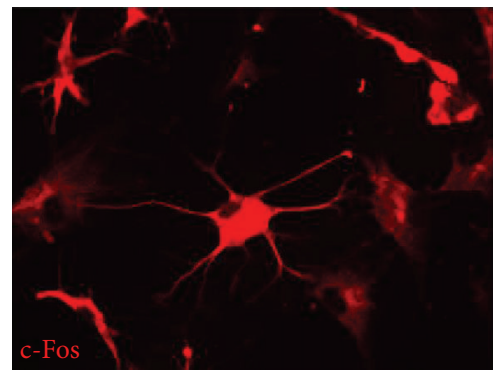

(h2)

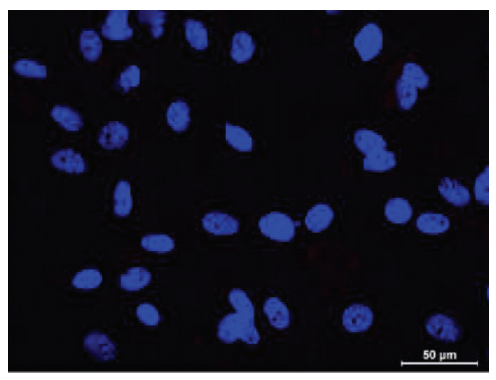

(c)

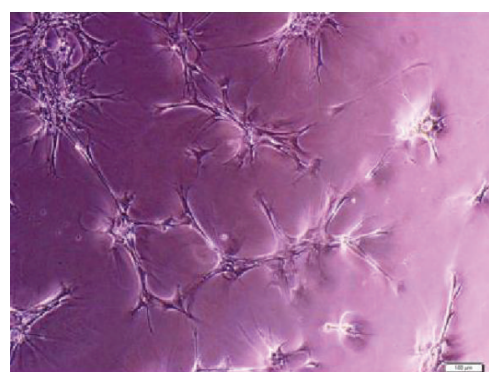

(f)

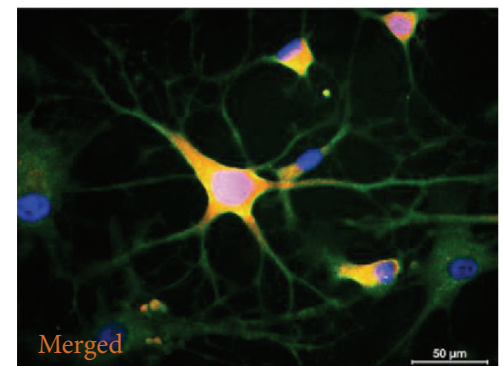

(g3)

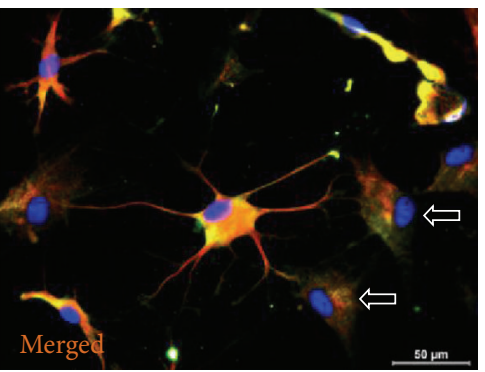

(h3)

(h)

Figure 3: Microscopic images of rAT-MSCs differentiated into adipocytes (a, b), osteoblasts (d), neuron-glial like cells (e), and endothelial cells (f). The arrows indicate the neutral lipid vacuoles stained with Oil Red O (b). rAT-MSCs were undifferentiated in standard culture medium (c). Phase contrast microscope images of the rAT-MSCs differentiated into osteogenic lineage, where calcified nodules (arrow) were stained with Alizarin red S (d). Differentiation of rAT-MSCs to neuron-glial like cells after 3 days (e). Endothelial tube formation by rATMSCs on Matrigel (f). Immunostaining of cells for GFAP (green) and beta-tubulin (red) differentiated cells (g1-g3). Increased cytoplasmic and nuclear staining of differentiated cells for c-Fos (red) and NF (green; cytoplasmic and membranous) was observed (h1-h3). 


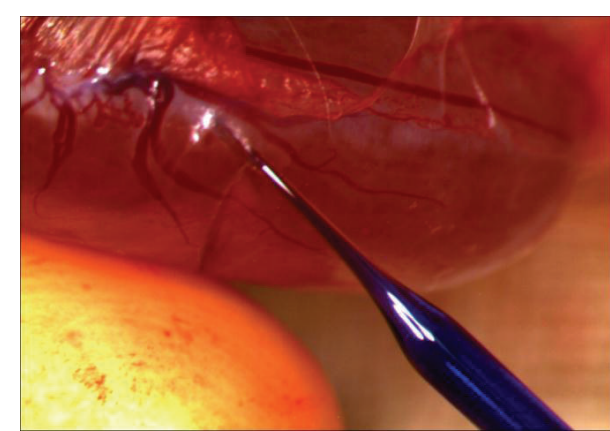

(a)

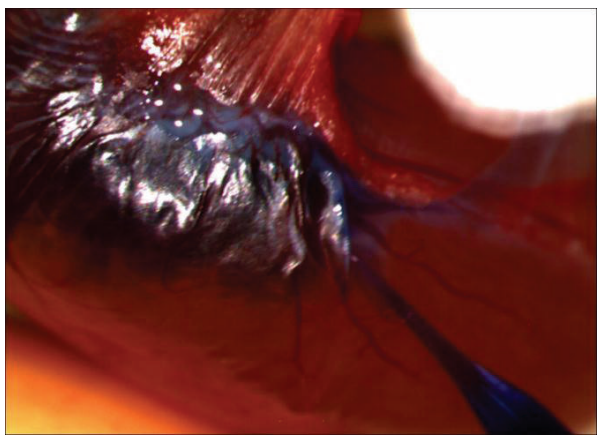

(c)

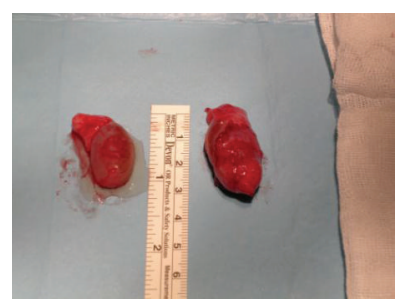

(e)

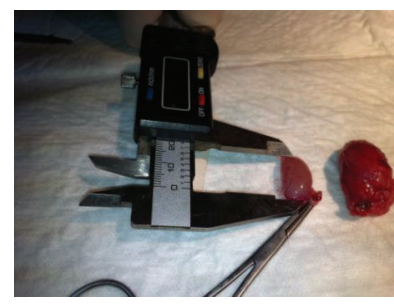

(f)

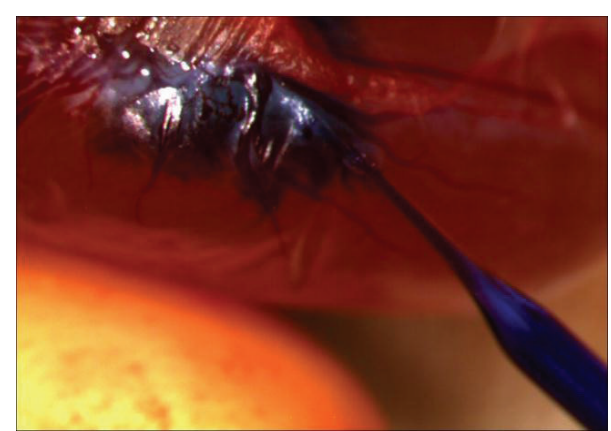

(b)

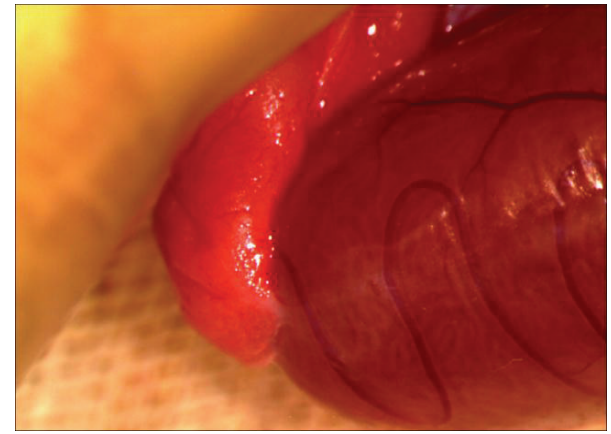

(d)

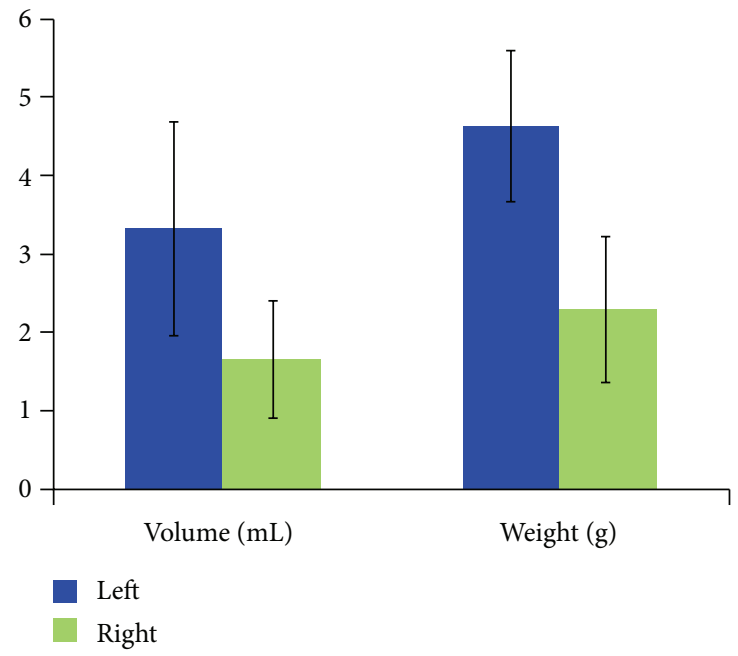

(g)

FiguRE 4: Cell transplantation into rete testis and morphological analyses of testes after 12 weeks. $1 \times 10^{6}$ cells were mixed with toluidine blue $(1: 1, \mathrm{v} / \mathrm{v})$, and the mixture was injected into the rete testis of the left testicle of rats $(\mathrm{a}-\mathrm{c})$. The right testicle of rats was left untreated after busulfan (d). After 12 weeks, the atrophy in right testicles (f) was significant, when compared with the left testicles with rAT-MSCs treatment (e). There were significant differences in both volume and weight of testicles: $P=0.0074$ and $P=0.0015$, respectively (g).

3.2. Immunostaining of $r A T-M S C$. Immunohistochemical studies were performed to characterize the progeny of the rAT-MSCs by using antibodies specific to known antigens of MSCs. Immune reactivity profile for rAT-MSCs was shown in Table 1. Under standard culture conditions, fibronectin (Figure 2(a)), GFAP (Figure 2(c)), Nestin (Figure 2(e)), Vimentin (Figure 2(f)), Map2a, b (Figure 2(g)), CD105, Collagen type-I, Collagen type-II, beta-tubulin, ASMA, Myogenin, Osteopontin, Osteocalcin, Osteonectin, Ki67,
PCNA, and Tenascin (data not shown) were expressed. Surface markers including CD34 (Figure 2(b)), CD45 (Figure 2(d)), Cytokeratin 18 (Figure 2(h)), and CD71 (Table 1) were not expressed by rAT-MSCs.

3.3. Differentiation Potential of rAT-MSCs. rAT-MSCs (P3) were differentiated within 3 weeks in the adipogenic differentiation medium. In cells, lipid droplets enlarged and invaded 


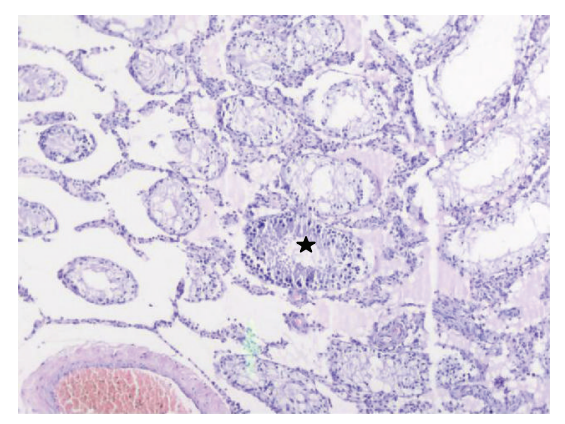

(a1)

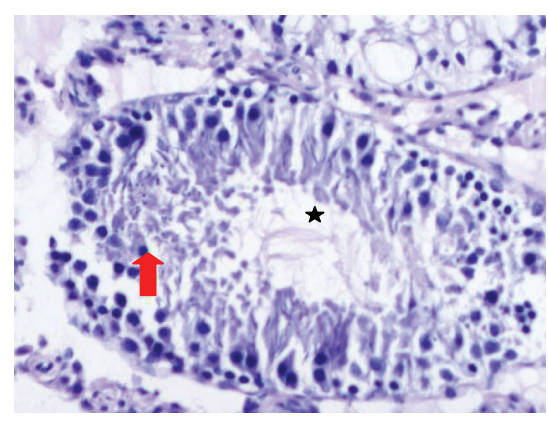

(a2)

(a)

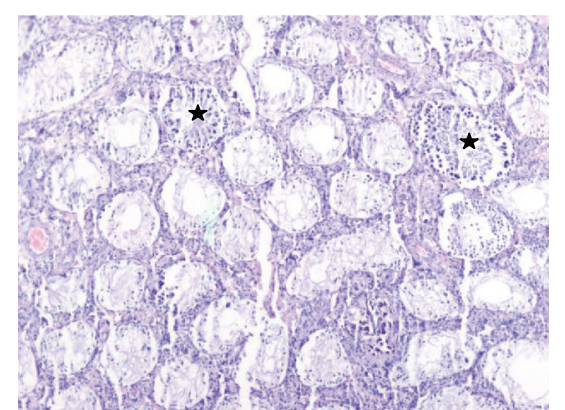

(b1)

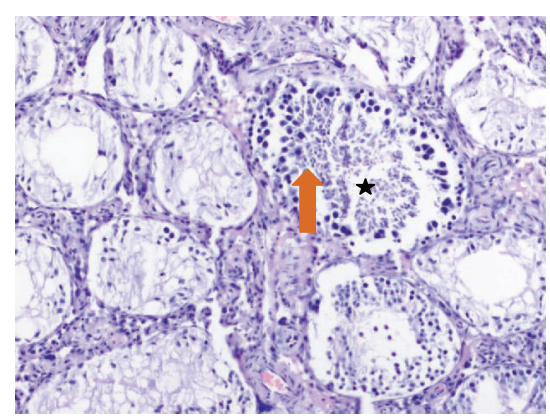

(b2)

(b)

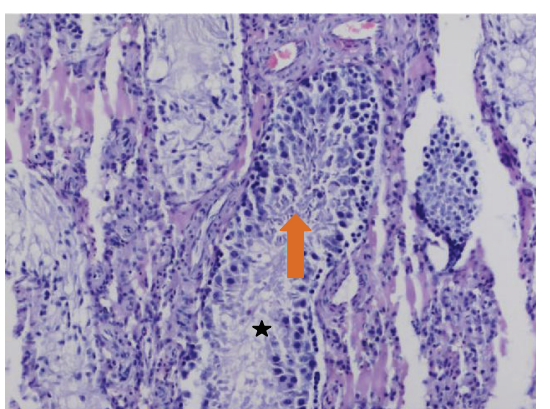

(c1)

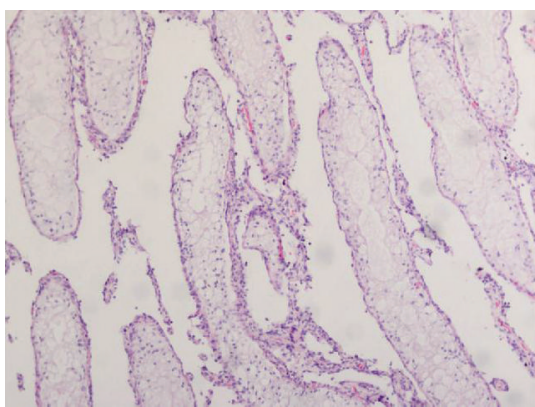

(d1)

(c)

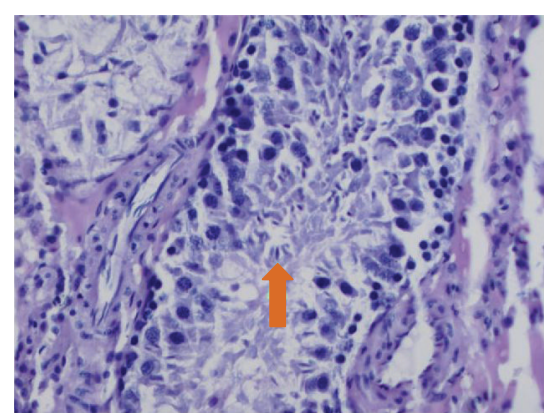

(c2)

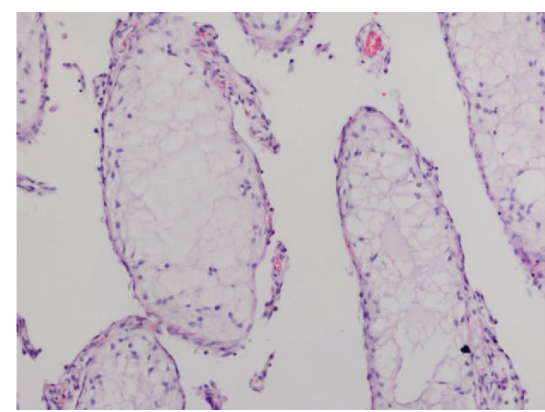

(d2)

(d)

FIGURE 5: Sections of treated testes with rAT-MSCs. Most of the seminiferous tubules were empty indicating the absence of spermatogenesis. Only a few tubules appeared to be filled with spermatogenetic cells up (asterisks). Spermatogenetic cells were shown in these tubules (red arrow) (a2). Spermatozoa were also shown with arrows (orange arrows) (b1, b2, and c2). Sections of busulfan-treated testis (right), which are not transplanted with stem cells, demonstrate empty seminiferous tubules that indicate no spermatogenetic activity (d1, d2). The higher magnification of the slides (a1, b1, c1, and d1) was shown on the right of the same sections (a2, b2, c2, and d2). Original magnifications: al, b1, d1-X48, c1, b2, d1-X100, a2, c2-X200. 


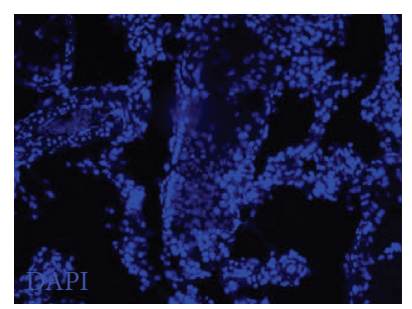

(a1)

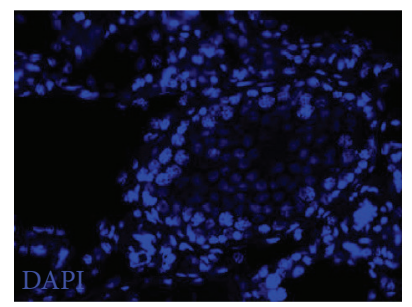

(b1)

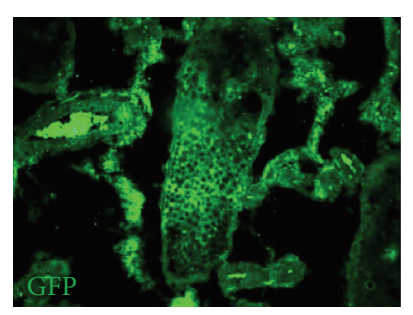

(a2)

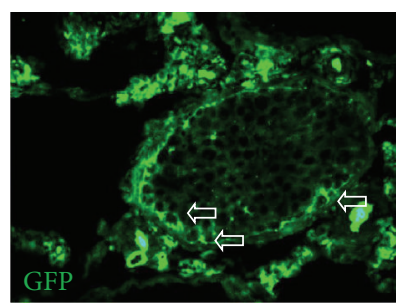

(b2)

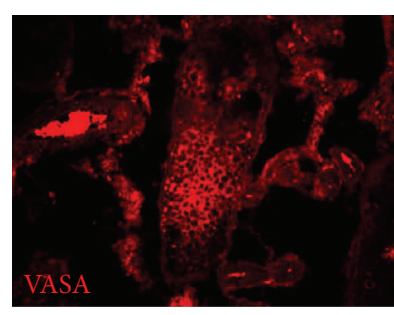

(a3)

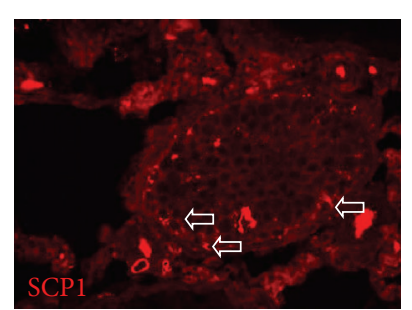

(b3)

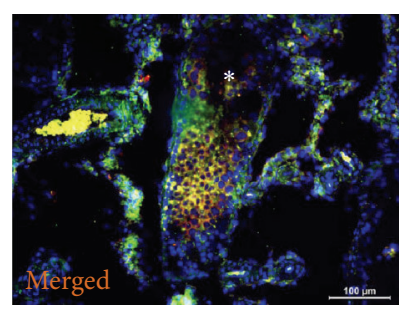

(a4)

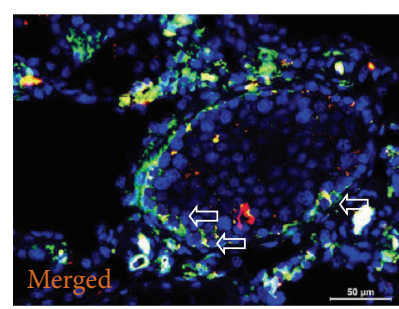

(b4)

(b)

FIGURE 6: Immunostaining of $\mathrm{GFP}^{+} / \mathrm{VASA}^{+}$and $\mathrm{GFP}^{+} / \mathrm{SCP}^{+}$cells in busulfan-treated testis with rAT-MSCs injection. $\mathrm{GFP}^{+} / \mathrm{VASA}^{+}$cells were localized in the seminiferous tubules of testis (white star), but most of the tubules were empty (blue asterisk) (al-a4). The expression of meiosis marker SCP1 in $\mathrm{GFP}^{+}$cells might indicate the transdifferentiation of MSCs into spermatogenic cells (white arrows) (b1-b4).

the entire cytoplasm (Figures 3(a) and 3(b)). The lipid droplet formation was not observed in undifferentiated rAT-MSCs (Figure 3(c)).

In the osteogenic differentiation, cells proliferated and reached almost complete confluency after 8-10 days of incubation. Later, the cellular aggregates were observed in differentiated cultures and the gradually increased. The aggregates were characterized by the presence of amorphous material deposits. These nodular aggregates in osteogenic cultures were stained with Alizarin red S after 28 days, demonstrating that the amorphous deposits were actually calcium deposits (Figure 3(d)).

rAT-MSC-derived neuron-like cells displayed distinct morphologies, ranging from extensively simple bipolar to large, branched multipolar cells (Figure 3(e)). Within $24 \mathrm{~h}$, these stem cells formed tube-like structures after culturing on Matrigel (Figure 3(f)). For characterizing their neuronal character further, differentiated rAT-MSCs were stained for neuron and glial cell specific markers including GFAP (Figures 3(g1) and 3(g3)), beta-Tubulin (Figures 3(g2) and 3(g3)), Neurofilament (Figures 3(h1) and 3(h3)), c-Fos (Figures 3(h2) and 3(h3)), Map-2a,b, beta3-Tubulin, Eno2, and HNK (data not shown).

3.4. Testicular Size and Spermatogenesis. The difference in dimensions of the left (treated with rAT-MSCs) and the right testicles (without cell transplantation) were analyzed, and mass increase of almost 50\% was measured in testes with rAT-MSCs (Figures 4(e), 4(f), and 4(g)). It was observed that the average volume of the testicles with rAT-MSCs was higher than the ones with no transplantation and atrophy was not seen in testicles with rAT-MSCs injection (Figures 4(e) and 4(f)). The volume increase of busulfan-treated testes was only observed significantly in the test subjects with MSCs transplantation (Figure 4(g)). A significant increase of size in other interstitial tissues was not noticed.

3.5. Histological Assessment of Spermatogenesis. Formalinfixed and paraffin-embedded testis tissue sections were stained with hematoxylin-eosin. These samples from stemcell-injected tissues were examined under light microscope for any spermatogenic activity. After generating the infertility in rat with double injection of $15 \mathrm{mg} / \mathrm{kg}$ of busulfan, the testes of the control animals were thoroughly analyzed for any spontaneous recovery of spermatogenesis, and no sign was observed for reinitiated spermatogenesis. The scanning of sections showed atrophy, complete, and incomplete spermatocytic arrest and Sertoli cell-only appearance for samples without rAT-MSCs. After the treatment with busulfan, spermatogenesis process was blocked (Figures 5(d1) and $5(\mathrm{~d} 2))$. However, the presence of spermatogonium in the tissues with stem cell transplantation was noted (Figures $5(\mathrm{a} 1)-5(\mathrm{c} 2))$. The seminiferous tubules of the controls, which were not treated with MSCs, were empty and indicated the disruption of spermatogenesis (Figures 5(d1) and 5(d2)). On the other hand, the tubules appeared to be filled up with spermatogenetic cells in the sections of cell-treated tissues, but with low rate. Spermatozoa were observed (Figures 5(a1)$5(c 2))$.

3.6. Detection of Spermatogenic Cells and Markers for Meiosis. The rAT-MSC-injected testis sections were positive for both GFP and VASA (Figures 6(a1)-6(a4) and 7). VASA-positive staining pointed to the presence of spermatogenic cells in 


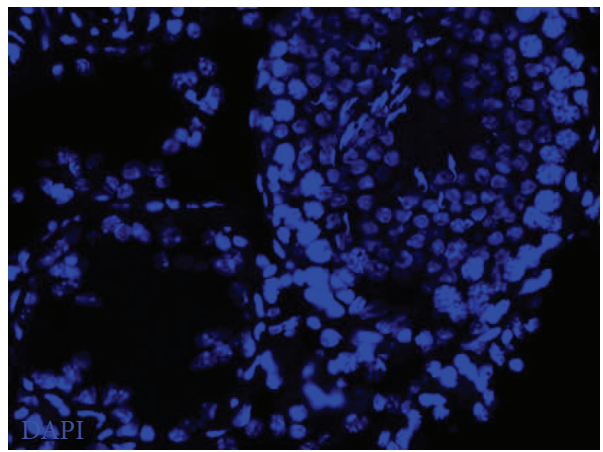

(a1)

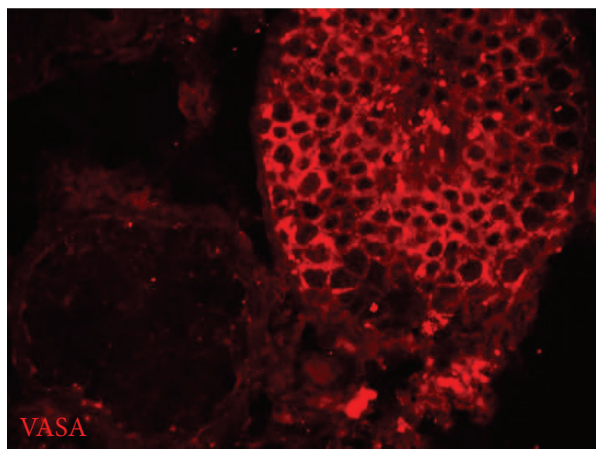

(a3)

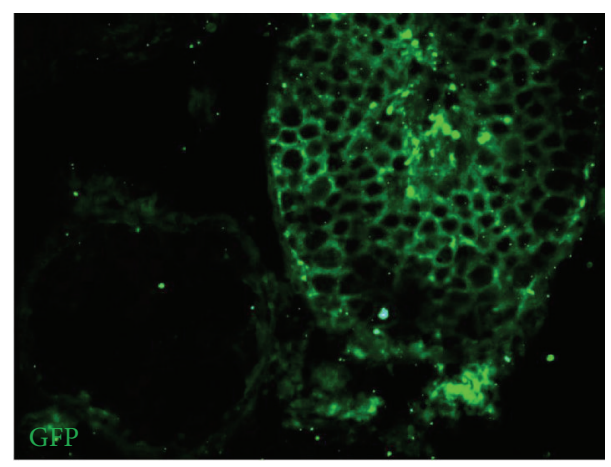

(a2)

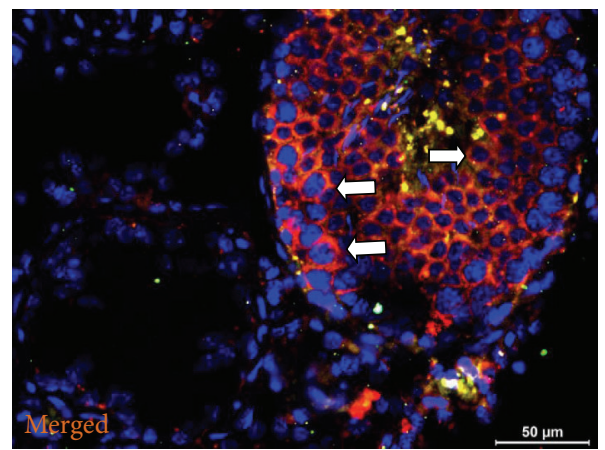

(a4)

FIGURE 7: GFP ${ }^{+}$cells in seminiferous tubule. MSC-received testis was fixed and stained for GFP (green) and spermatogenic cell marker, VASA (red). The cells in seminiferous tubule with dual staining were shown by arrows (a4). The adjacent tubules showed no staining for VASA, which indicated the absence of spermatogenic activity.

tubules, and the GFP staining designated the origin of cells to be the rAT-MSCs used in transplantation. Interestingly, not all $\mathrm{GFP}^{+}$cells were expressing VASA (germ cell marker). However, the $\mathrm{GFP}^{+}$and VASA ${ }^{+}$cells (yellow) might indicated that those cells possibly underwent in the sperm formation process in tubules. The expression of meiosis marker, SCP1, also supported the evidence of participation of rAT-MSC in spermatogenesis (Figures 6(b1)-6(b4)). Both markers were not expressed in the undifferentiated state of $\mathrm{rAT}$-MSC in cell culture in vitro (see in Supplementary Material available on line at http://dx.doi.org/10.1155/2013/529589. Data 1).

3.7. Restoration of Male Fertility and Birth of Offspring. After mating and successful pregnancy periods following pairing of female rats with male rats with GFP-labeled rAT-MSCs, 9 viable offspring were obtained (Figures $8(\mathrm{al})-8(\mathrm{a} 4)$ ). These male rats were further mated with other females, and the preserved fertility was observed in stem-cell-transplanted animals by obtaining the next offspring. To determine whether the offspring were originated from stem-cell-treated males' spermatozoa, $0.4 \mathrm{~mL}$ of blood of each animal was collected for DNA isolation and detection of GFP gene in genome. GFP gene was detected by PCR and Southern blot hybridization (Figures 9(a) and 9(b)). The fragment of expected size (634 bp) was amplified in conventional PCR. Exogenous gene integration into genome of offspring was also shown by Southern blot hybridization for GFP (Figure 9(b)). Because the parental rats lack the GFP gene, the only possible origin of this foreign gene in offspring would be the GFP gene used to label rAT-MSCs prior to the injection in testes. The copy number of GFP gene was estimated to be equal to the reference gene, Sox2, by real-time PCR. The gene copy was also estimated in rAT-MSCs before transplantation to be the same as Sox2 gene (Figure 9(c)). The MSCs were isolated from the bone marrow and adipose tissue of the offspring (Figures 10 and 11). The immunostaining of those cells with GFP antibody gave positive result, meaning that both types of MSCs inherited their GFP gene from the paternal rats and were functionally expressed in their cytoplasm like the rATMSCs injected in testes. The location of the GFP expression was observed in cytoplasm, but very close to the nuclei. The same staining pattern was also observed in the cell culture of $\mathrm{GFP}^{+}$rAT-MSCs (see Supplementary Data 2). The only possible source of this nonmammalian gene could be the GFP labeled rAT-MSCs, injected in infertile male rats, it could be considered as a significant evidence for the maturation of functional sperms from injected rAT-MSCs. In the analysis of $\mathrm{GFP}^{+}$cells, MSCs were deliberately selected because of the complexity of mammalian gene expression regulation and being aware of GFP was previously expressed in MSCs. In addition, the presence of GFP was also detected in the sperms of offspring (see Supplementary Data 3). The sperm cells were stained with GFP antibody to increase the intensity of 


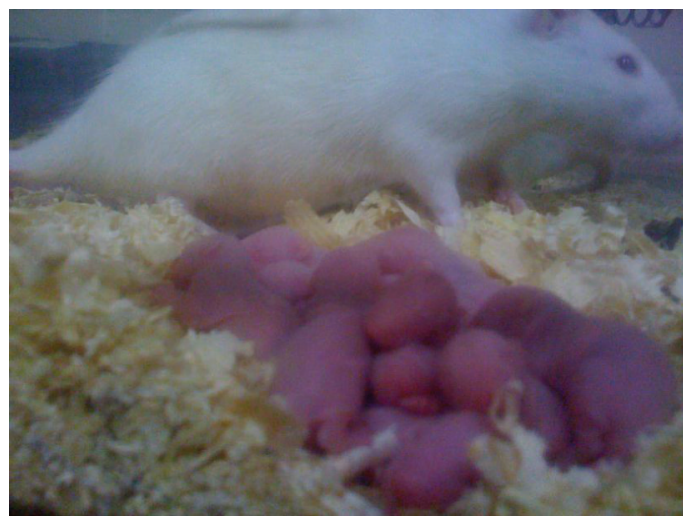

(a1)

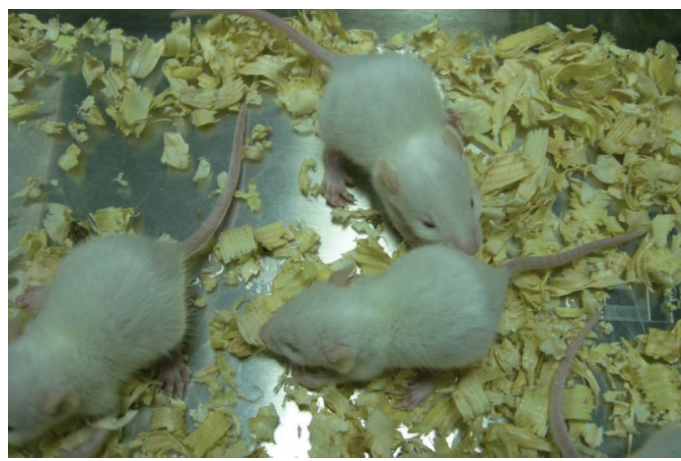

(a3)

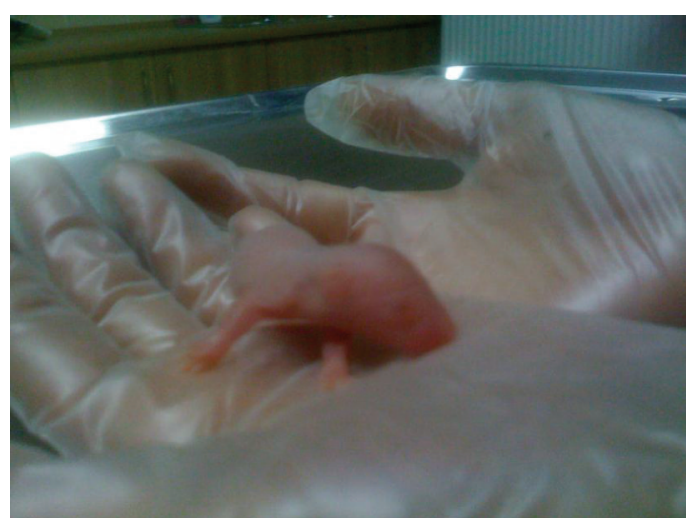

(a2)

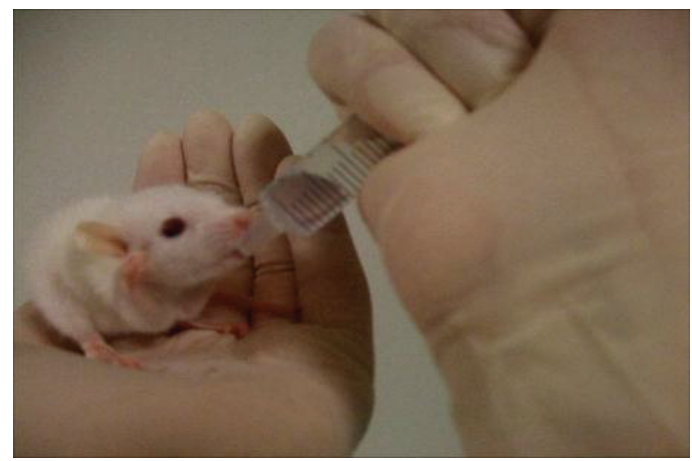

(a4)

FIGURE 8: Newborns (offspring) after pairing healthy females with rAT-MSC-injected males with busulfan-treated testes. Offspring after birth (a1-a2) and after 10 days (a3-a4).

green light and their nuclei were shown by DAPI. The sperm cells were observed with GFP accumulation overlying the nuclei. This transgenic rat line has been propagated to the third generation by inbreeding without silencing of transgene expression.

\section{Discussion}

The development of stem-cell-based therapies currently represents one of the major challenges of medical research. Adipose-tissue-derived mesenchymal stromal cells could be obtained from the stromal vascular fraction [32] under in vitro culture conditions. These cells are characterized by fibroblast-like morphology, adherence to plastic surfaces, continuous cell proliferation over long culture periods and multilineage differentiation capacity. They could transdifferentiate into variety tissue cells including endothelial, epithelial, muscle, Schwann cells, hepatocytes and neurons in vitro $[15,32-42]$.

In infertility and sterility, stem cell therapy promises to be a potential source of male and female germ cells. Not only ESCs but also fetal porcine skin stem cells, human fetal lung-MSCs, bone marrow, and umbilical cord MSCs were the candidate for the germ cell differentiation in vitro
$[20,23,25,28,43-46]$. On the other hand, stem cells experimentally derived from bone marrow have been recently used in experimental busulfan-treated infertility rodent models. Nayernia et al. [23, 24] showed for the first time that murine BM-MSCs could differentiate into male germ cells. Yazawa et al. [47] proved that MSCs have the capacity to differentiate into steroidogenic cells, such as Leydig cells, both in vivo and in vitro [46]. More recently, Lue et al. [26] showed that BM-MSCs, transplanted into testis of a busulfantreated infertility mouse model, appeared to differentiate into germ cells, Sertoli cells, and Leydig cells [26]. This finding raises the possibility of using MSCs to treat male infertility and testosterone deficiency. The general consensus on AT- and BM-MSC is that they are virtually identical in cell surface marker profile, gene expression profile, and differentiation potential [12]. This issue has been confirmed in a preclinical study in which both cells were found equally effective in treating a porcine model of cardiac infarction [17]. Whereas bone marrow could only be obtained in limited quantity, the adipose tissue is usually available in abundance. Therefore, the difference in the clinical application potential of AT-MSC and BM-MSC is quite obvious [1]. Numerous studies conducted to date have indicated that stem cells derived from adult human tissues could be reprogrammed to differentiate into different cell types. However, no progress or evidence has been reported so far in the isolation and 


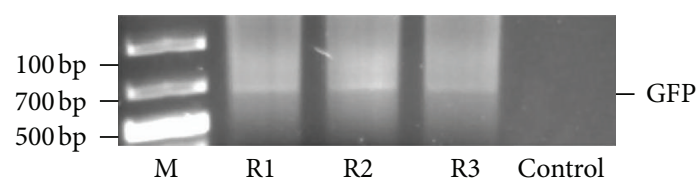

(a)

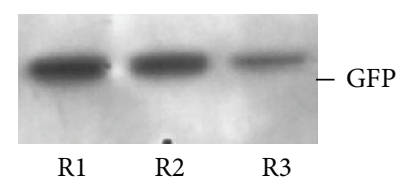

(b)

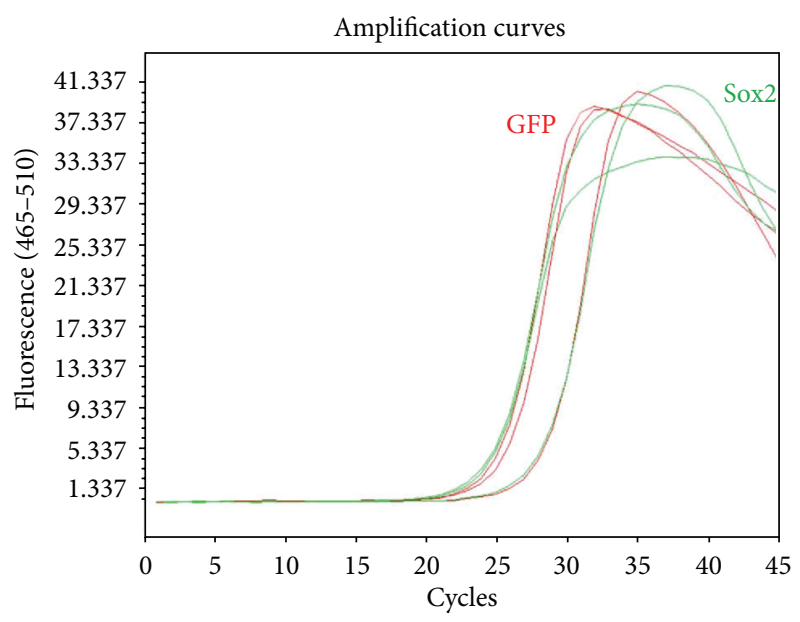

(c)

FIGURE 9: Representative analysis of chromosomal DNA for exogenous gene (GFP) insertion for three offspring (R1-R3). DNA isolated from blood samples were analyzed for GFP gene by PCR amplification (a) and southern blot hybridization (b). Gene copy number of GFP and Sox2 in genome was estimated to be same by Real-Time PCR (c). The GFP gene in chromosomal DNA of rat supported the evidence for transdifferentiation of MSCs into functional sperms.

characterization of AT-MSCs to differentiate into functional germ cells. This study showed the differentiation potential of clonally expanded MSCs into germ cells or sperm-like cells. The transplantation of AT-MSCs was successfully achieved into testis through rete testis of busulfan-treated infertility rat models. Later, there was observed the recovery of the fertile status of those males. The analyses also supported the evidences of the functional spermatogenesis progress in testes.

The expression of GFP and the meiosis marker, SCP1, by these cells in tubules might indicate the involvement of rAT-MSC in spermatogenesis. The function of MSCs in spermatogenesis might be direct (transdifferentiation), or they interact with niche of testis tissue. Reprogramming might be achieved by changing the cellular microenvironment (niche), in which the cells grow, to provide signals that might activate appropriate metabolic pathways. Successful experiments were performed in vivo by using the microenvironment of the target cell type. When the conditions were provided similar to the in vivo microenvironment, differentiation of stem cells into the targeted cell types with full functionality could be obtained also in vitro [48-58]. In the study by Kim et al., it was indicated that the niche might include some factors that promote the genetic and epigenetic status of stem cell selfrenewal in vitro [27]. Most importantly the niche was pointed out for serving as a cellular platform for the expansion of stem cells that could potentially be exploited for therapeutic tissue/organ neogenesis.
The entire process of spermatogenesis from spermatogonial stem cells (SSCs) to spermatozoa takes place in the seminiferous tubules. SSCs involve into regeneration and maintenance of spermatogenesis and are located in the basal compartment, also recognized as niche. This site was defined as specialized microenvironment necessary for maintenance of stem cells. This concept was first proposed by Schofield in 1978 for the hematopoietic cell system [59]. According to this hypothesis, stem cells cannot survive long enough to function as SSCs outside of the basal compartment niche. Therefore, a stem cell needs this niche to proliferate in controlled manner and to execute its role in the body. There might be several important players in SSC niche formation: Sertoli cells, the basement membrane, peritubular myoid cells, and undefined signals external to the seminiferous tubules. Sertoli cells might be the most important component, as they provide growth factors for SSCs and have been described to insinuate themselves between all of the neighboring germ cells, leaving very few regions with evident contact between germ cells. Recent studies have demonstrated that Sertoli-cellderived growth factor, glial-cell-line-derived neurotrophic factor, plays a key role to promote SSC survival and selfrenewal, thereby stimulating SSC proliferation in vivo and in vitro [60-64]. rAT-MSCs, injected in the testes, were localized both in and out of the seminiferous tubules, from which SSCs were removed by busulfan treatment. As soon as the migrated MSCs had contact with the niche in the seminiferous tubules and with the cytokines secreted by 


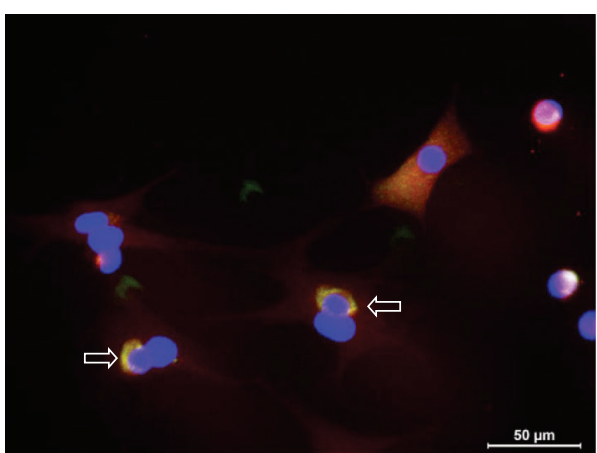

(a1)

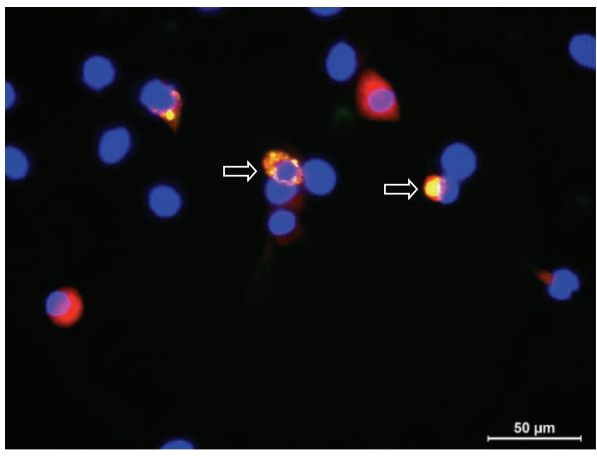

(a3)

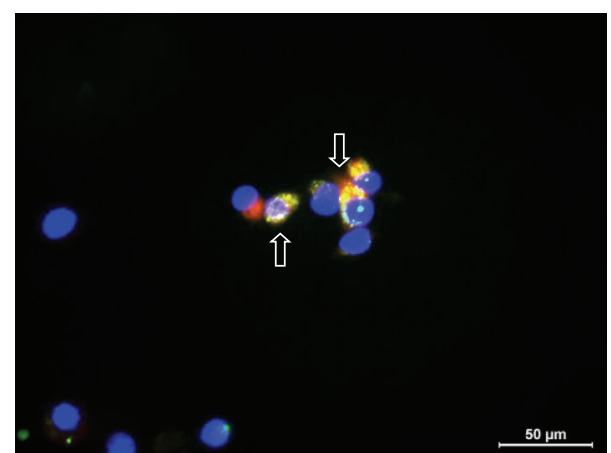

(a2)

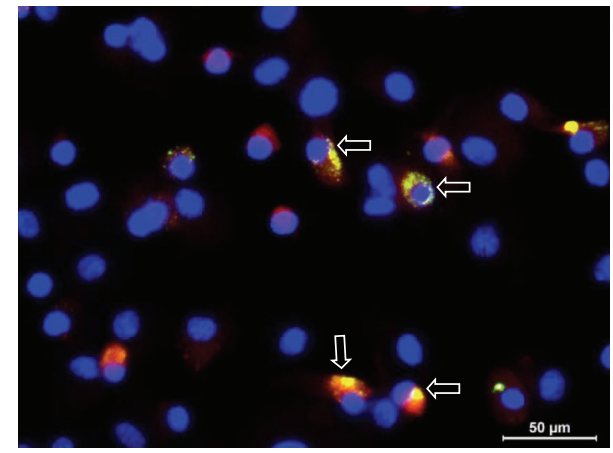

(a4)

Figure 10: $\mathrm{GFP}^{+} /$Vimentin $^{+}$mesenchymal stem cells derived from bone marrow (P0) from offspring. rBM-MSCs were isolated from the offspring (al-a4), and some vimentin- (red) positive cells showed the GFP (green) expression (arrows). The expression of nonmammalian gene GFP in rBM-MSCs indicates the transdifferentiation of GFP-labeled rAT-MSCs in testes.

the Sertoli cells, they might transdifferentiated into SSCs and initiate the spermatogenesis. This specific microenvironment could provide a unique and excellent condition for meiosis and functional sperm formation to MSCs. Therefore, the rATMSCs demonstrated a better differentiation into functional sperm compared to the in vitro differentiation studies.

The main handicap of the busulfan treatment in rat models was the possibility of severe destruction of niche, especially Sertoli cells in testes. This damage could be the explanation of why the spermatogenesis was not started in all seminiferous tubules, but the activity was limited only in a couple of tubules. The destruction of Sertoli cells by busulfan treatment caused the damaged of niche, such that it did not have the capacity to support the transdifferentiation of migrated rAT-MSCs anymore. It was considered that the niche might play a vital role in differentiation of rAT-MSCs into functional sperm.

The differentiation of insufficient number of cells and the high number of cells in the phase of incomplete meiosis are considered the two main drawbacks of germ-like cell derivation of stem cells [64]. In those studies, small number of cells after busulfan treatment was positive for specific germ cell markers, like VASA and SCPs. The differentiation took place not in all but in some tubules. In our study, the busulfan treatment was proven to be effective in elimination of cells in tubules, but the overexposure might also cause the damage of niche. The spermatogenesis activity was only observed to start in a few tubules, but it was sufficient to initiate successful pregnancy.

The male rats recovered their fertility after receiving the injection of AT-MSCs. The stem cells could affect either by maintaining the preexisting SSCs leading to reinitiate the spermatogenesis or by transdifferentiation into SSC-like cells to form spermatocytes. To explain this event, the AT-MSCs were transferred with GFP gene before injection in testes, and the integrity of this gene into genome was assured. Following mating and pregnancy, the first generation of offspring was obtained. The sperms recovered from the offspring were $\mathrm{GFP}^{+}$. MSCs isolated from the tissues of offspring were analyzed, and GFP was shown to be expressed in cells by immunostaining. Although this exogenous gene was integrated into genomic DNA, GFP expression was not observed in all cells of offspring. The GFP gene was transferred for reporting purpose and not for generating a transgenic animal. The vector was designed to express GFP gene in cells under the control of CMV promoter. Hypermethylation of the viral promoter sequences by de novo DNA methylation in host cells might cause silencing of the transgene in some cells and in next generations [65]. But the important point is that the only origin of GFP could be the rAT-MSCs injected into the testes. The results indicated that these cells transdifferentiated into functional sperm in seminiferous tubules, and these sperms later involved in delivery of GFP gene to offspring genome. As the sperm formation was not observed in vitro 


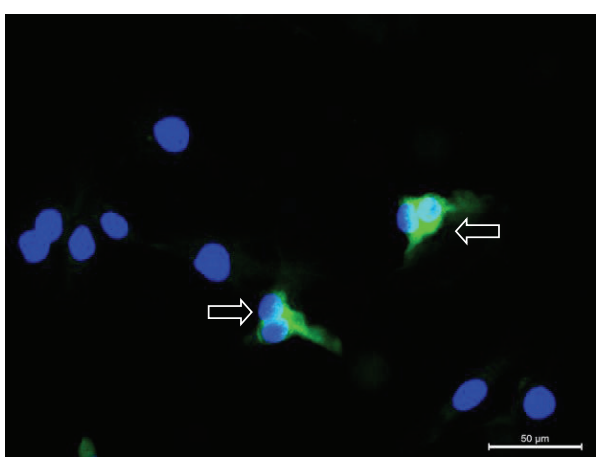

(a1)

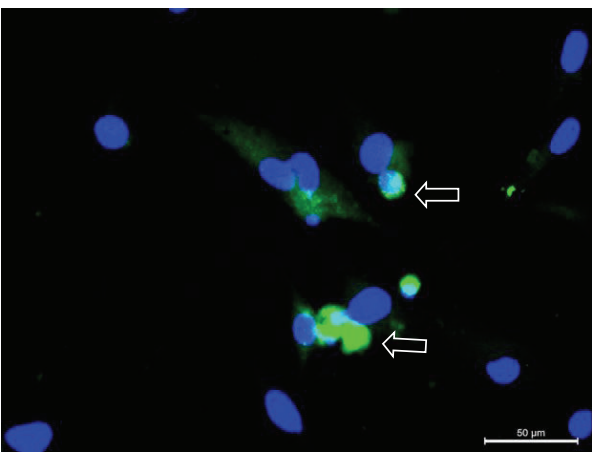

(b1)

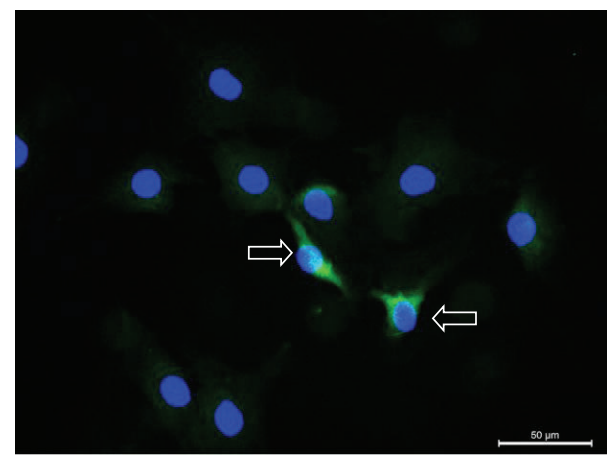

(a2)

(a)

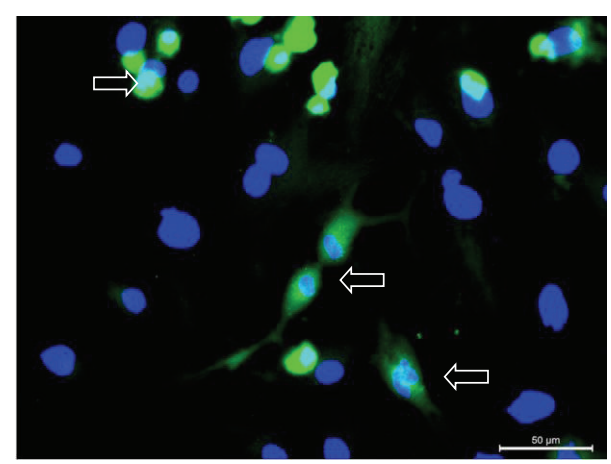

(b2)

(b)

FIGURE 11: GFP ${ }^{+}$rBM- and rAT-MSCs (P2) derived from offspring. MSCs were isolated and characterized from the bone marrow (a1-a2) and adipose tissue (b1-b2) of offspring. The GFP-gene could only be originated from the paternal rat injected with GFP labeled rAT-MSCs.

and also in severely damaged tubules, it might point to the significance of the well-preserved niche for the differentiation MSCs into sperm. There is also another possibility, which should be taken into account, that the MSCs had the characteristics to fuse with other cells spontaneously [66]. From the early studies with MSCs, it was well known that these cells could fuse with somatic cells, albeit rarely. It was found that the frequency of fusion between MSCs and differentiated cells increased in the presence of TNF-alpha and/or IFNgamma [67]. The apoptosis was induced in testes by busulfan, and these cytokines were highly expressed, consequently. The increase in the fusion events was expected in testes. It should be noticed that there was a period of 12 weeks between the busulfan treatment and MSCs injection, and the inflammatory factors were reduced during this period. For spermatogenesis activity, MSCs should form hybrid cell with existing SSCs. However, the severe damage by busulfan eliminated almost all SSCs in tubules, and the only cells left were Sertoli cells. Although they are very important for niche, they could not have the capacity for spermatogenesis. Therefore, the fusion could not have played a significant role in the recovery of infertility.

On the other hand, the expression of pluripotency markers by rAT-MSCs might have an effect on sperm generation. Although the mesenchymal stem cells are generally classified as multipotent with respect to their differentiation capacity, the expression of these pluripotency markers could enhanced their differentiation potential into various tissues [68]. Obviously, it was not enough for sperm generation from MSCs in cell culture. Some additional factors might be required that could be provided by niche. The expression levels of some pluripotency genes (Oct4, Sox2, Rexl, and FoxD3) were analyzed for the same rAT-MSC line (unpublished data). The expression for Sox 2 and FoxD3 could not be detected, but there was relatively strong expression of Rexl and weak expression of Oct4. The expression of Rexl is known to preserve the undifferentiated state of stem cells. This gene was also suggested to be important in spermatocytes, and it might play a role in meiosis [69]. Beside the effect of niche, the intrinsic factors, like expression of Rexl, might also have direct or indirect effects on sperm generation.

In conclusion, the fertile status of busulfan treated-male rats was recovered by rAT-MSCs transplantation in this study. The $\mathrm{GFP}^{+}$cells were found both outside of the basal compartment and in the seminiferous tubules, supporting the idea that MSCs might have functioned in reestablishment of spermatogenesis by two ways: MSCs' differentiation into sperm, or maintenance of SSCs. These results showed the rAT-MSCs could be both rich and functional source for the infertility treatment. The most important issue of this 
study was the achievement of first successful results in spermatogenesis by endogen reprogramming using adult stem cells. If this protocol was also proven to be functional in human, the possibility to treat the males with azoospermia would arouse.

\section{Conflict of Interests}

The authors declare that they have no conflict of interests.

\section{Acknowledgments}

The authors thank Alparslan Okcu for his technical assistance during this study. They would like to express sincere thanks to Proffessor Dr. Mustafa Ark and Dr. Müzeyyen Astarcı for guidance and to A. Begum Bugdaycı Acikkol for her efforts in animal supply and care. This study was supported by the Scientific and Technological Research Council of Turkey (110S506).

\section{References}

[1] C. Y. Lin, B. S. Lee, C. C. Liao, W. J. Cheng, F. M. Chang, and M. H. Chen, "Transdifferentiation of bone marrow stem cells into acinar cells using a double chamber system," Journal of the Formosan Medical Association, vol. 106, no. 1, pp. 1-7, 2007.

[2] M. Stashower, K. Smith, J. Williams, and H. Skelton, "Stromal progenitor cells present within liposuction and reduction abdominoplasty fat for autologous transfer to aged skin," Dermatologic Surgery, vol. 25, no. 12, pp. 945-949, 1999.

[3] Y. C. Halvorsen, W. O. Wilkison, and J. M. Gimble, "Adiposederived stromal cells-their utility and petential in bone formation," International Journal of Obesity, vol. 24, no. 4, pp. S41-S44, 2000.

[4] Y. D. C. Halvorsen, D. Franklin, A. L. Bond et al., "Extracellular matrix mineralization and osteoblast gene expression by human adipose tissue-derived stromal cells," Tissue Engineering, vol. 7, no. 6, pp. 729-741, 2001.

[5] Y. D. C. Halvorsen, A. Bond, A. Sen et al., "Thiazolidinediones and glucocorticoids synergistically induce differentiation of human adipose tissue stromal cells: biochemical, cellular, and molecular analysis," Metabolism: Clinical and Experimental, vol. 50, no. 4, pp. 407-413, 2001.

[6] S. Gronthos, D. M. Franklin, H. A. Leddy, P. G. Robey, R. W. Storms, and J. M. Gimble, "Surface protein characterization of human adipose tissue-derived stromal cells," Journal of Cellular Physiology, vol. 189, no. 1, pp. 54-63, 2001.

[7] A. Sen, Y. R. Lea-Currie, D. Sujkowska et al., "Adipogenic potential of human adipose derived stromal cells from multiple donors is heterogeneous," Journal of Cellular Biochemistry, vol. 81, no. 2, pp. 312-319, 2001.

[8] P. Wu, K. Sato, S. Yukawa, Y. Hikasa, and K. Kagota, "Differentiation of stromal-vascular cells isolated from canine adipose tissues in primary culture," Journal of Veterinary Medical Science, vol. 63, no. 1, pp. 17-23, 2001.

[9] P. A. Zuk, M. Zhu, H. Mizuno et al., "Multilineage cells from human adipose tissue: implications for cell-based therapies," Tissue Engineering, vol. 7, no. 2, pp. 211-228, 2001.

[10] T. S. Housman, N. Lawrence, B. G. Mellen et al., "The safety of liposuction: results of a national survey," Dermatologic Surgery, vol. 28 , no. 11, pp. 971-978, 2002.
[11] S. Lendeckel, A. Jödicke, P. Christophis et al., "Autologous stem cells (adipose) and fibrin glue used to treat widespread traumatic calvarial defects: case report," Journal of CranioMaxillofacial Surgery, vol. 32, no. 6, pp. 370-373, 2004.

[12] B. M. Strem, K. C. Hicok, M. Zhu et al., "Multipotential differentiation of adipose tissue-derived stem cells," The Keio Journal of Medicine, vol. 54, no. 3, pp. 132-141, 2005.

[13] B. Fang, Y. P. Song, L. M. Liao, Q. Han, and R. C. Zhao, "Treatment of severe therapy-resistant acute graft-versus-host disease with human adipose tissue-derived mesenchymal stem cells," Bone Marrow Transplantation, vol. 38, no. 5, pp. 389-390, 2006.

[14] T. A. Moseley, M. Zhu, and M. H. Hedrick, "Adipose-derived stem and progenitor cells as fillers in plastic and reconstructive surgery," Plastic and Reconstructive Surgery, vol. 118, no. 3, pp. 121-128, 2006.

[15] H. Ning, G. Lin, T. F. Lue, and C. S. Lin, "Neuron-like differentiation of adipose tissue-derived stromal cells and vascular smooth muscle cells," Differentiation, vol. 74, no. 9-10, pp. 510518, 2006.

[16] B. Fang, Y. Song, Q. Lin et al., "Human adipose tissue-derived mesenchymal stromal cells as salvage therapy for treatment of severe refractory acute graft-vs.-host disease in two children," Pediatric Transplantation, vol. 11, no. 7, pp. 814-817, 2007.

[17] C. Valina, K. Pinkernell, Y. H. Song et al., "Intracoronary administration of autologous adipose tissue-derived stem cells improves left ventricular function, perfusion, and remodelling after acute myocardial infarction," European Heart Journal, vol. 28, no. 21, pp. 2667-2677, 2007.

[18] K. Yoshimura, K. Sato, N. Aoi, M. Kurita, T. Hirohi, and K. Harii, "Cell-assisted lipotransfer for cosmetic breast augmentation: supportive use of adipose-derived stem/stromal cells," Aesthetic Plastic Surgery, vol. 32, no. 1, pp. 48-55, 2008.

[19] Y. Toyooka, N. Tsunekawa, R. Akasu, and T. Noce, "Embryonic stem cells can form germ cells in vitro," Proceedings of the National Academy of Sciences of the United States of America, vol. 100, no. 20, pp. 11457-11462, 2003.

[20] N. Geijsen, M. Horoschak, K. Kim, J. Gribnau, K. Eggan, and G. Q. Daley, "Derivation of embryonic germ cells and male gametes from embryonic stem cells," Nature, vol. 427, no. 6970, pp. 148-154, 2004.

[21] J. A. West, I. H. Park, G. Q. Daley, and N. Geijsen, "In vitro generation of germ cells from murine embryonic stem cells," Nature Protocols, vol. 1, no. 4, pp. 2026-2036, 2006.

[22] K. Nayernia, M. Li, L. Jaroszynski et al., "Stem cell based therapeutical approach of male infertility by teratocarcinoma derived germ cells," Human Molecular Genetics, vol. 13, no. 14, pp. 1451-1460, 2004.

[23] K. Nayernia, J. Nolte, H. W. Michelmann et al., "In vitrodifferentiated embryonic stem cells give rise to male gametes that can generate offspring mice," Developmental Cell, vol. 11, no. 1, pp. 125-132, 2006.

[24] K. Nayernia, J. H. Lee, N. Drusenheimer et al., "Derivation of male germ cells from bone marrow stem cells," Laboratory Investigation, vol. 86, no. 7, pp. 654-663, 2006.

[25] N. Drusenheimer, G. Wulf, J. Nolte et al., "Putative human male germ cells from bone marrow stem cells," Society of Reproduction and Fertility Supplement, vol. 63, pp. 69-76, 2007.

[26] Y. Lue, K. Erkkila, P. Y. Liu et al., "Fate of bone marrow stem cells transplanted into the testis: potential implication for men with testicular failure," American Journal of Pathology, vol. 170, no. 3, pp. 899-908, 2007. 
[27] J. Kim, M. Seandel, I. Falciatori, D. Wen, and S. Rafii, "CD34+ testicular stromal cells support long-term expansion of embryonic and adult stem and progenitor cells," Stem Cells, vol. 26, no. 10, pp. 2516-2522, 2008.

[28] J. Hua, P. Qiu, H. Zhu, H. Cao, F. Wang, and W. Li, "Multipotent mesenchymal stem cells (MSCs) from human umbilical cord: potential differentiation of germ cells," African Journal of Biochemistry Research, vol. 5, no. 4, pp. 113-123, 2011.

[29] M. L. Meistrich and M. Kangasniemi, "Hormone treatment after irradiation stimulates recovery of rat spermatogenesis from surviving spermatogonia," Journal of Andrology, vol. 18, no. 1, pp. 80-87, 1997.

[30] T. Ogawa, J. M. Aréchaga, M. R. Avarbock, and R. L. Brinster, "Transplantation of testis germinal cells into mouse seminiferous tubules," International Journal of Developmental Biology, vol. 41, no. 1, pp. 111-122, 1997.

[31] E. Southern, "Southern blotting," Nature Protocols, vol. 1, no. 2, pp. 518-525, 2006.

[32] P. A. Zuk, M. Zhu, P. Ashjian et al., "Human adipose tissue is a source of multipotent stem cells," Molecular Biology of the Cell, vol. 13, no. 12, pp. 4279-4295, 2002.

[33] K. M. Safford, K. C. Hicok, S. D. Safford et al., "Neurogenic differentiation of murine and human adipose-derived stromal cells," Biochemical and Biophysical Research Communications, vol. 294, no. 2, pp. 371-379, 2002.

[34] P. H. Ashjian, A. S. Elbarbary, B. Edmonds et al., "In vitro differentiation of human processed lipoaspirate cells into early neural progenitors," Plastic and Reconstructive Surgery, vol. 111, no. 6, pp. 1922-1931, 2003.

[35] S. K. Kang, D. H. Lee, Y. C. Bae, H. K. Kim, S. Y. Baik, and J. S. Jung, "Improvement of neurological deficits by intracerebral transplantation of human adipose tissue-derived stromal cells after cerebral ischemia in rats," Experimental Neurology, vol. 183, no. 2, pp. 355-366, 2003.

[36] S. S. Tholpady, A. J. Katz, and R. C. Ogle, "Mesenchymal stem cells from rat visceral fat exhibit multipotential differentiation in vitro," Anatomical Record Part A, vol. 272, no. 1, pp. 398-402, 2003.

[37] S. K. Kang, L. A. Putnam, J. Ylostalo et al., "Neurogenesis of Rhesus adipose stromal cells," Journal of Cell Science, vol. 117, no. 18, pp. 4289-4299, 2004.

[38] A. C. Boquest, A. Shahdadfar, K. Frønsdal et al., "Isolation and transcription profiling of purified uncultured human stromal stem cells: alteration of gene expression after in vitro cell culture," Molecular Biology of the Cell, vol. 16, no. 3, pp. 1131-1141, 2005.

[39] J. Fujimura, R. Ogawa, H. Mizuno, Y. Fukunaga, and H. Suzuki, "Neural differentiation of adipose-derived stem cells isolated from GFP transgenic mice," Biochemical and Biophysical Research Communications, vol. 333, no. 1, pp. 116-121, 2005.

[40] F. Guilak, K. E. Lott, H. A. Awad et al., "Clonal analysis of the differentiation potential of human adipose-derived adult stem cells," Journal of Cellular Physiology, vol. 206, no. 1, pp. 229-237, 2006.

[41] S. K. Kang, M. J. Shin, J. S. Jung, Y. G. Kim, and C. H. Kim, "Autologous adipose tissue-derived stromal cells for treatment of spinal cord injury," Stem Cells and Development, vol. 15, no. 4, pp. 583-594, 2006.

[42] T. Nagase, D. Matsumoto, M. Nagase et al., "Neurospheres from human adipose tissue transplanted into cultured mouse embryos can contribute to craniofacial morphogenesis: a preliminary report," Journal of Craniofacial Surgery, vol. 18, no. 1, pp. 49-53, 2007.

[43] A. T. Clark, M. S. Bodnar, M. Fox et al., "Spontaneous differentiation of germ cells from human embryonic stem cells in vitro," Human Molecular Genetics, vol. 13, no. 7, pp. 727-739, 2004.

[44] P. W. Dyce, L. Wen, and J. Li, "In vitro germline potential of stem cells derived from fetal porcine skin," Nature Cell Biology, vol. 8, no. 4, pp. 384-390, 2006.

[45] O. Lacham-Kaplan, H. Chy, and A. Trounson, “Testicular cell conditioned medium supports differentiation of embryonic stem cells into ovarian structures containing oocytes," Stem Cells, vol. 24, no. 2, pp. 266-273, 2006.

[46] J. Hua, H. Yu, W. Dong et al., "Characterization of mesenchymal stem cells (MSCs) from human fetal lung: potential differentiation of germ cells," Tissue and Cell, vol. 41, no. 6, pp. 448-455, 2009.

[47] T. Yazawa, T. Mizutani, K. Yamada et al., "Differentiation of adult stem cells derived from bone marrow stroma into Leydig or adrenocortical cells," Endocrinology, vol. 147, no. 9, pp. 41044111, 2006.

[48] S. G. Ball, A. C. Shuttleworth, and C. M. Kielty, "Direct cell contact influences bone marrow mesenchymal stem cell fate," International Journal of Biochemistry and Cell Biology, vol. 36, no. 4, pp. 714-727, 2004.

[49] M. Koyanagi, R. P. Brandes, J. Haendeler, A. M. Zeiher, and S. Dimmeler, "Cell-to-cell connection of endothelial progenitor cells with cardiac myocytes by nanotubes: a novel mechanism for cell fate changes?" Circulation Research, vol. 96, no. 10, pp. 1039-1041, 2005.

[50] C. Lange, H. Bruns, D. Kluth, A. R. Zander, and H. C. Fiegel, "Hepatocytic differentiation of mesenchymal stem cells in cocultures with fetal liver cells," World Journal of Gastroenterology, vol. 12, no. 15, pp. 2394-2397, 2006.

[51] S. M. Richardson, R. V. Walker, S. Parker et al., "Intervertebral disc cell-mediated mesenchymal stem cell differentiation," Stem Cells, vol. 24, no. 3, pp. 707-716, 2006.

[52] F. J. Rivera, W. D. Sierralta, J. J. Minguell, and L. Aigner, "Adult hippocampus derived soluble factors induce a neuronal-like phenotype in mesenchymal stem cells," Neuroscience Letters, vol. 406, no. 1-2, pp. 49-54, 2006.

[53] T. Wang, Z. Xu, W. Jiang, and A. Ma, "Cell-to-cell contact induces mesenchymal stem cell to differentiate into cardiomyocyte and smooth muscle cell," International Journal of Cardiology, vol. 109, no. 1, pp. 74-81, 2006.

[54] K. L. Doyle, A. Kazda, Y. Hort, S. M. McKay, and S. Oleskevich, "Differentiation of adult mouse olfactory precursor cells into hair cells in vitro," Stem Cells, vol. 25, no. 3, pp. 621-627, 2007.

[55] I. C. Lee, J. H. Wang, Y. T. Lee, and T. H. Young, "The differentiation of mesenchymal stem cells by mechanical stress or/and co-culture system," Biochemical and Biophysical Research Communications, vol. 352, no. 1, pp. 147-152, 2007.

[56] C. S. Lin, Z. C. Xin, C. H. Deng, H. Ning, G. Lin, and T. F. Lue, "Recent advances in andrology-related stem cell research," Asian Journal of Andrology, vol. 10, no. 2, pp. 171-175, 2008.

[57] X. T. Meng, D. Chen, Z. Y. Dong, and J. M. Liu, "Enhanced neural differentiation of neural stem cells and neurite growth by amniotic epithelial cell co-culture," Cell Biology International, vol. 31, no. 7, pp. 691-698, 2007.

[58] Y. Yamada, S. I. Yokoyama, N. Fukuda et al., "A novel approach for myocardial regeneration with educated cord blood cells 
cocultured with cells from brown adipose tissue," Biochemical and Biophysical Research Communications, vol. 353, no. 1, pp. 182-188, 2007.

[59] R. Schofield, "The relationship between the spleen colonyforming cell and the haemopoietic stem cell. A hypothesis," Blood Cells, vol. 4, no. 1-2, pp. 7-25, 1978.

[60] X. Meng, M. Lindahl, M. E. Hyvönen et al., "Regulation of cell fate decision of undifferentiated spermatogonia by GDNF," Science, vol. 287, no. 5457, pp. 1489-1493, 2000.

[61] Y. Tadokoro, K. Yomogida, H. Ohta, A. Tohda, and Y. Nishimune, "Homeostatic regulation of germinal stem cell proliferation by the GDNF/FSH pathway," Mechanisms of Development, vol. 113, no. 1, pp. 29-39, 2002.

[62] M. Kanatsu-Shinohara, N. Ogonuki, K. Inoue et al., "Long-term proliferation in culture and germline transmission of mouse male germline stem cells," Biology of Reproduction, vol. 69, no. 2, pp. 612-616, 2003.

[63] H. Kubota, M. R. Avarbock, and R. L. Brinster, "Growth factors essential for self-renewal and expansion of mouse spermatogonial stem cells," Proceedings of the National Academy of Sciences of the United States of America, vol. 101, no. 47, pp. 16489-16494, 2004.

[64] K. T. Ebata, J. R. Yeh, X. Zhang, and M. C. Nagano, "Soluble growth factors stimulate spermatogonial stem cell divisions that maintain a stem cell pool and produce progenitors in vitro," Experimental Cell Research, vol. 317, no. 10, pp. 1319-1329, 2011.

[65] D. Jahner and R. Jaenisch, "Chromosomal position and specific demethylation in enhancer sequences of germ line-transmitted retroviral genomes during mouse development," Molecular and Cellular Biology, vol. 5, no. 9, pp. 2212-2220, 1985.

[66] A. Z. Rizvi, J. R. Swain, P. S. Davies et al., "Bone marrow-derived cells fuse with normal and transformed intestinal stem cells," Proceedings of the National Academy of Sciences of the United States of America, vol. 103, no. 16, pp. 6321-6325, 2006.

[67] K. Kemp, D. Gordon, D. C. Wraith et al., "Fusion between human mesenchymal stem cells and rodent cerebellar Purkinje cells," Neuropathology and Applied Neurobiology, vol. 37, no. 2, pp. 166-178, 2011.

[68] R. Gonzalez, L. Griparic, V. Vargas et al., "A putative mesenchymal stem cells population isolated from adult human testes," Biochemical and Biophysical Research Communications, vol. 385, no. 4, pp. 570-575, 2009.

[69] D. M. Kristensen, J. E. Nielsen, N. E. Skakkebaek et al., "Presumed pluripotency markers UTF-1 and REX-1 are expressed in human adult testes and germ cell neoplasms," Human Reproduction, vol. 23, no. 4, pp. 775-782, 2008. 

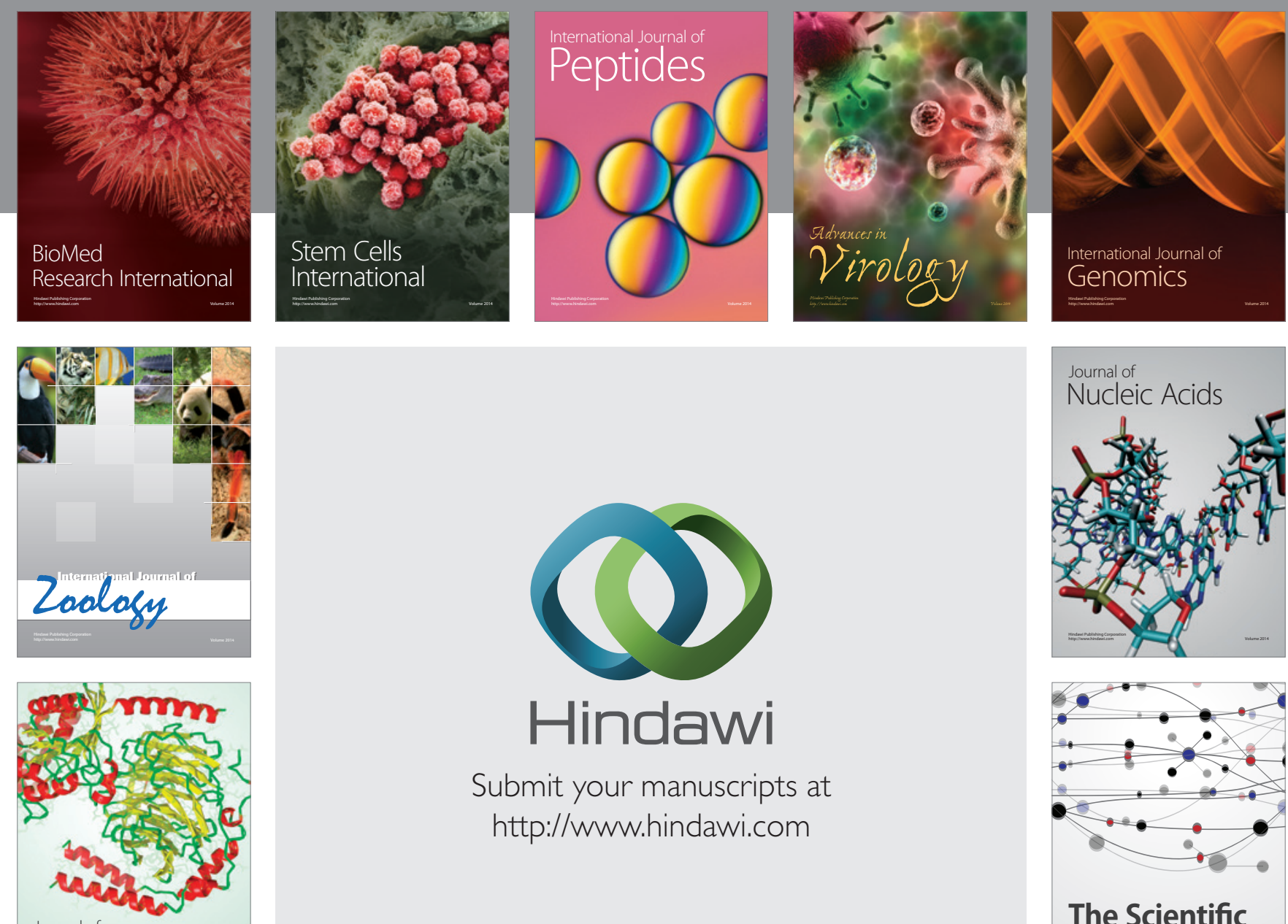

Submit your manuscripts at

http://www.hindawi.com

Journal of
Signal Transduction
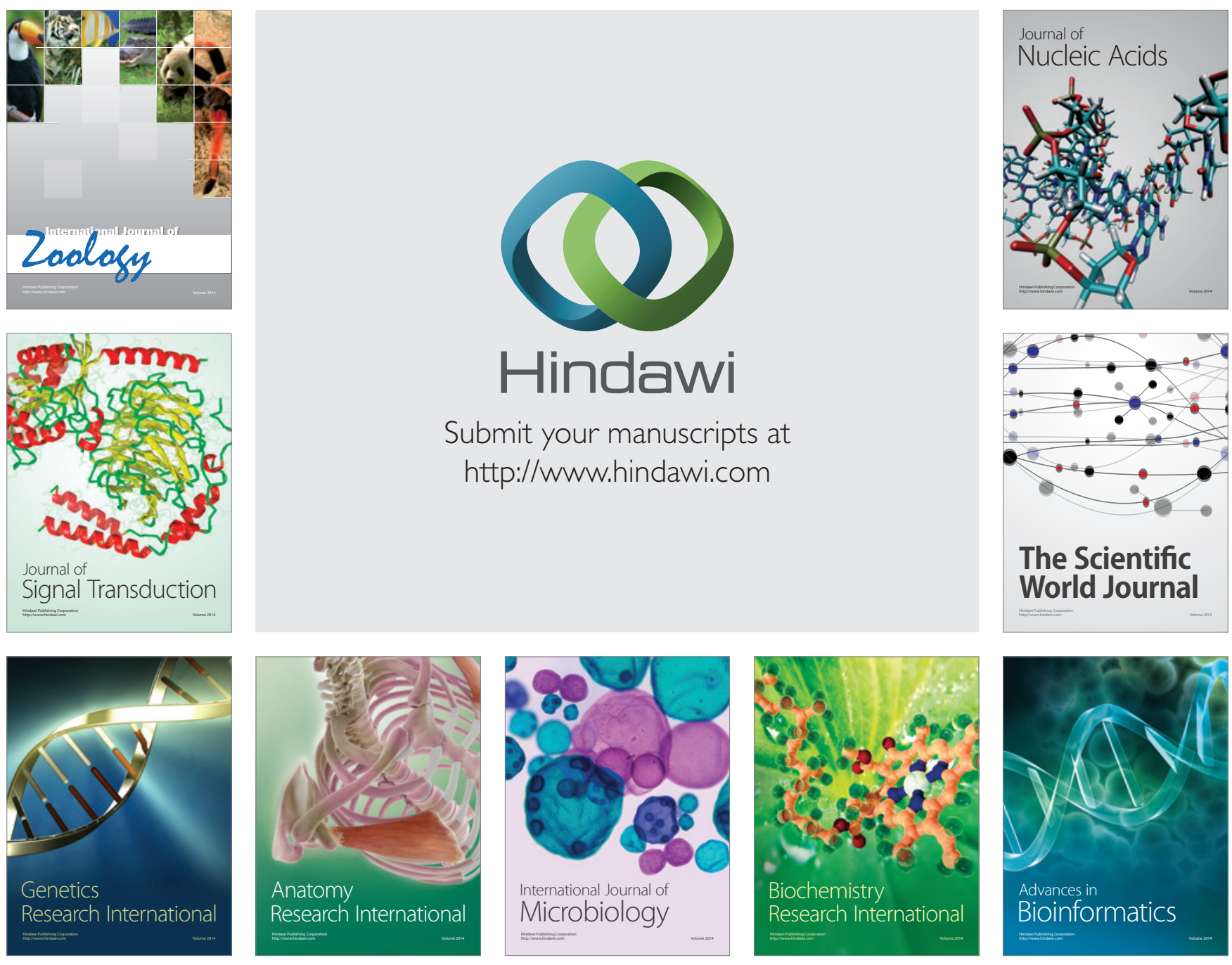

The Scientific World Journal
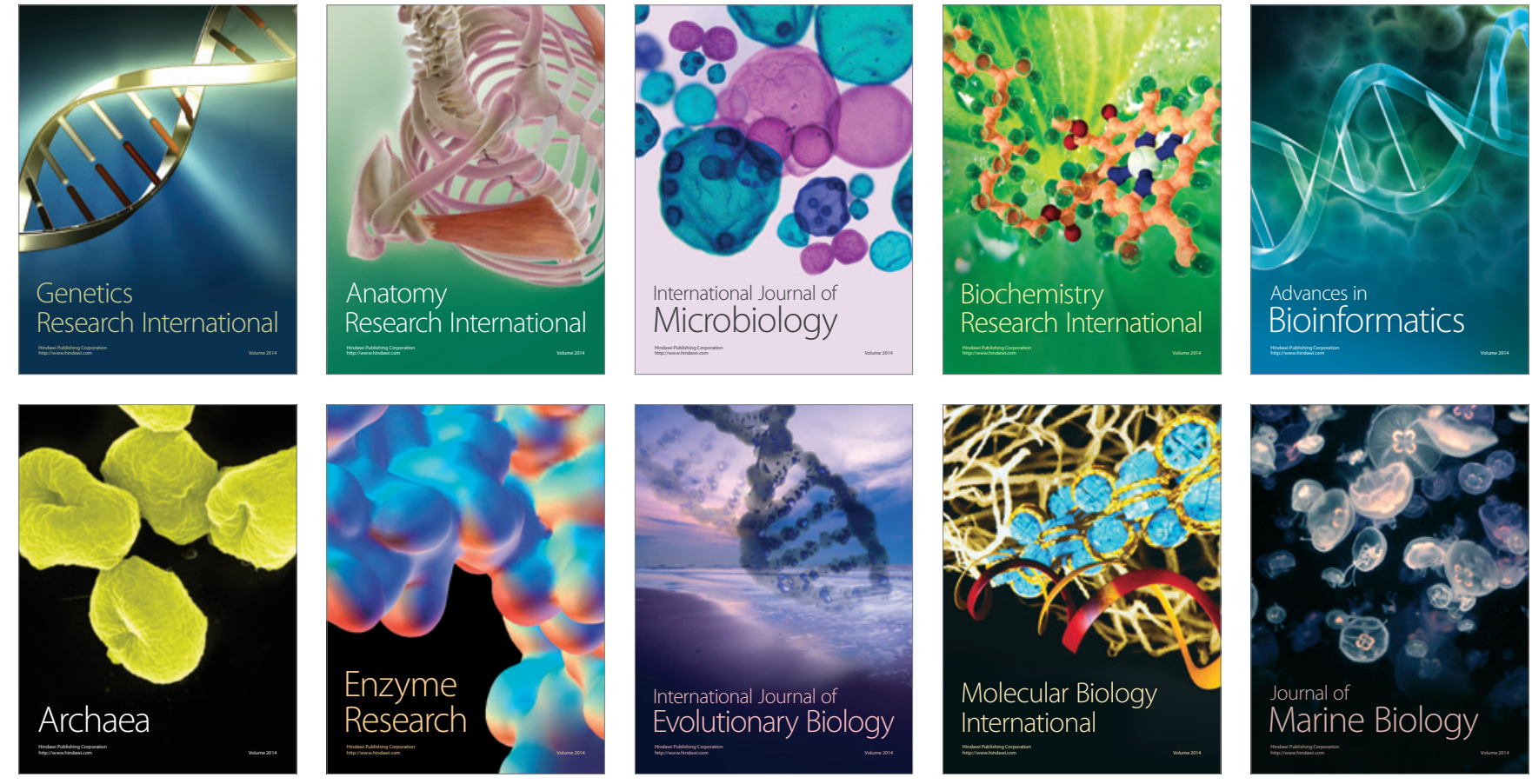